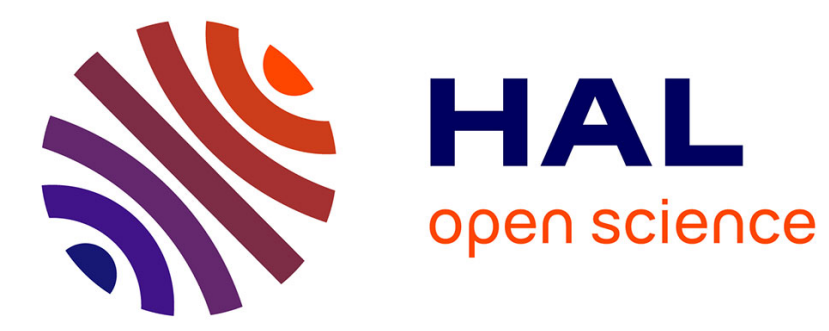

\title{
The nano-architecture of the axonal cytoskeleton
}

Christophe Leterrier, Pankaj Dubey, Subhojit Roy

\section{To cite this version:}

Christophe Leterrier, Pankaj Dubey, Subhojit Roy. The nano-architecture of the axonal cytoskeleton. Nature Reviews Neuroscience, 2017, 18 (12), pp.713 - 726. 10.1038/nrn.2017.129 . hal-01701366

\section{HAL Id: hal-01701366 https://hal.science/hal-01701366}

Submitted on 6 Feb 2018

HAL is a multi-disciplinary open access archive for the deposit and dissemination of scientific research documents, whether they are published or not. The documents may come from teaching and research institutions in France or abroad, or from public or private research centers.
L'archive ouverte pluridisciplinaire HAL, est destinée au dépôt et à la diffusion de documents scientifiques de niveau recherche, publiés ou non, émanant des établissements d'enseignement et de recherche français ou étrangers, des laboratoires publics ou privés. 


\title{
REVIEWS
}

\section{The nano-architecture of the axonal cytoskeleton}

\author{
Christophe Leterrier', Pankaj Dubey ${ }^{2}$ and Subhojit Roy ${ }^{2,3}$
}

Abstract | The corporeal beauty of the neuronal cytoskeleton has captured the imagination of generations of scientists. One of the easiest cellular structures to visualize by light microscopy, its existence has been known for well over 100 years, yet we have only recently begun to fully appreciate its intricacy and diversity. Recent studies combining new probes with super-resolution microscopy and live imaging have revealed surprising details about the axonal cytoskeleton and, in particular, have discovered previously unknown actin-based structures. Along with traditional electron microscopy, these newer techniques offer a nanoscale view of the axonal cytoskeleton, which is important for our understanding of neuronal form and function, and lay the foundation for future studies. In this Review, we summarize existing concepts in the field and highlight contemporary discoveries that have fundamentally altered our perception of the axonal cytoskeleton.

${ }^{1}$ NeuroCyto, Neurobiologie des Interactions Cellulaires et Neurophysiopathologie (NICN) Unités Mixtes de Recherche (UMR) 7259, Aix Marseille Université, Centre National de la Recherche Scientifique (CNRS), 3344 Cedex 15, Marseille, France. ${ }^{2}$ Department of Pathology and Laboratory Medicine, University of WisconsinMadison.

${ }^{3}$ Department of Neuroscience University of WisconsinMadison, 1111 Highland Avenue, Madison, Wisconsin 53705, USA

Correspondence to C.L. and S.R. christophe.leterrier@univamu.fr;

roy27@wisc.edu

doi:10.1038/nrn.2017.129 Published online 3 Nov 2017

Corrected online 16 Nov 2017
The cytoskeleton is a cellular shapeshifter. Like these creatures of mythology and speculative fiction, the cytoskeleton can alter its physical form and shape to accommodate the immediate needs of the cell. Indeed, many a rapt student has watched the cytoskeleton of a dividing cell seemingly miraculously transform into an organized mitotic spindle and then dissolve into an indiscrete mass, right before their eyes. The extreme polarization of neurons (that is, their fundamental asymmetry, arising due to the presence of elongated processes), along with their lifelong plasticity, creates unique demands on the cytoskeleton. A remarkable example is the axon, which can grow to enormous lengths and must generate and maintain its form and function throughout life - a burden that rests largely on the cytoskeleton.

The axonal cytoskeleton has three major constituents: microtubules, neurofilaments and actin (BOX 1). Each is unique, associating with its own set of binding proteins and performing specialized roles within the axon. Most of these cytoskeletal proteins are synthesized in the neuronal soma and are transported along the axon. Such transport is a constitutive phenomenon that occurs throughout the life of the neuron. Thus, the axonal cytoskeleton is best understood by considering both its anatomical organization and its dynamics (including axonal transport).

Given the complex morphology and physiology of neurons, the field of neurobiology has traditionally been at the forefront of adopting new optical technologies as they arise. Advances in microscopy now allow us to observe cells with unprecedented spatial resolution and to follow dynamic processes with exquisite temporal detail ${ }^{1}$. For example, super-resolution strategies that circumvent the diffraction limit of optical microscopy appeared more than ten years ago (BOX 2) and have been used to reveal aspects of neuronal organization down to the scale of macromolecular complexes $^{2}$. These techniques have provided key insights into the organization and function of the axonal cytoskeleton - and in particular the organization of actin and microtubules - revealing how it builds the axon and maintains its intricate architecture. Focusing on the cytoskeleton within the axon initial segment (AIS) and the more distal axon shaft, in this Review, we highlight these recent discoveries and place them in the context of earlier findings, giving the reader a tentative vision of the future.

\section{Overview of the axonal cytoskeleton}

The history of cytoskeletal research is essentially the pursuit of tools and techniques that allowed an evercloser view of this elaborate structure, a quest that continues to this day. Early studies by 17 th-century microscopy pioneers highlighted a network of 'neurofibrils', which we now know were most likely neurofilaments ${ }^{3}$. With the advent of electron microscopy, two types of fibrils were seen in axons: filaments measuring approximately $10 \mathrm{~nm}$ in diameter, corresponding to neurofilaments, and others measuring approximately $20-30 \mathrm{~nm}$ in diameter, corresponding to structures that eventually came to be known as microtubules ${ }^{4,5}$. 


\section{Box 1 | The components of the cytoskeleton}

Microtubules are present in all eukaryotic cells and play essential roles in cell division, the movement of cellular organelles and structural support. They are composed of 13 protofilaments, which are organized into a cylinder of $25 \mathrm{~nm}$ diameter. Each protofilament is made of heterodimers composed of $\alpha$-tubulin and $\beta$-tubulin, which are arranged in an alternating pattern. These heterodimers bind GTP, which is progressively hydrolysed to GDP after assembly. Microtubules are polar structures, with a fast-growing 'plus' end and a slower-growing 'minus' end.

Actin filaments (also known as F-actin) are found in all eukaryotes and play critical roles in cell motility, division, adhesion, signalling and many other fundamental processes. Actin filaments are approximately $8 \mathrm{~nm}$ in diameter, composed of actin monomers (known as G-actin) and require ATP for polymerization. Actin filaments have a defined polarity, with a barbed (rapidly growing) end at which monomer exchange is greater than it is at the other (pointed) end.

Neurofilaments are the intermediate filaments of neurons, measuring approximately $10 \mathrm{~nm}$ in diameter. They provide mechanical support to the axon and regulate axon diameter. Neurofilaments are heteropolymers, composed of subunits of high, medium and low molecular weight as well as internexin or peripherin intermediate filaments. Each neurofilament subunit has a short amino-terminal globular head domain, a central conserved alpha-helical rod domain and a variable carboxy-terminal tail domain. The central rod domain co-assembles with other subunits to form dimers, protofilaments and filaments. Unlike actin and microtubules, neurofilaments are not polarized and do not require ATP or GTP for polymerization.

\section{Electron microscopy A group of methods that generate an image of a sample by using a beam of electrons. Electrons can be detected after passing through the sample (transmission electron microscopy) or after being reflected (scanning electron microscopy). Electron microscopy can routinely reach $1 \mathrm{~nm}$ resolution (the size of a single amino acid) but usually requires the sample to be placed in a vacuum and is therefore destructive and most applicable to fixed samples labelled with specific procedures.}

Immuno-electron

microscopy

An electron microscopy modality in which proteins labelled by using antibodies that are tagged with small gold beads are imaged, allowing their localization.

\section{Microtubule}

plus-end-tracking proteins A set of proteins that bind the growing plus ends of microtubules. The core components of this complex are end-binding proteins, dimeric proteins that interact with the specific tubulin conformation found at the plus end.
As electron microscopy techniques improved, they revealed a surprisingly complicated cytoskeletal network in axons, composed of intermingled neurofilaments and microtubules and numerous 'side arms' and 'cross bridges' (REFS 6,7). At the same time, biochemical studies indicated that these cytoskeletal polymers were composed of building blocks, or subunits, providing a fundamental insight into their biogenesis $^{8,9}$. Although actin filaments were long known to be present in muscle, these linear polymers were eventually also identified in various non-muscle cells, including neurons ${ }^{10}$.

The evolution of electron microscopy also led to the identification of a new anatomical and physiological compartment along the first $20-60 \mu \mathrm{m}$ of the axon shaft: the AIS. The AIS is of exceptional interest because it is the region within which axon potentials are initiated (reviewed in REF. 11). The AIS is characterized by a unique cytoskeletal organization that has two striking features: small fascicles of microtubules and a dense sub-axolemmal undercoat ${ }^{12-14}$. Unlike the more distal axon, where microtubules are uniformly dispersed within the cross section of the axoplasm, microtubules in the AIS are arranged in fascicles in which 3-6 closely apposed microtubules are connected by electron-dense cross bridges $^{13}$ (FIG. 1). This unique clustering was suggested to have a role in directing the polarized trafficking of vesicles and organelles into the axon ${ }^{15,16}$. The undercoat ${ }^{17}$ was shown to contain a dense complex of cytoskeletal proteins (including actin, spectrin and ankyrin-G, also known as ankyrin 3) that tethers an array of membrane proteins, including voltage-gated sodium and potassium channels and cell adhesion molecules (CAMs) ${ }^{18-22}$. The membrane proteins anchored at the AIS were later shown to create a diffusion barrier between the cell body and the axon ${ }^{23,24}$.
Although the picture painted by electron microscopy suggested a static structure, other studies hinted that the axonal cytoskeleton was dynamic. One clue came from pulse-chase radiolabelling studies that examined axonal transport of the cytoskeletal components. In these experiments, newly synthesized proteins were labelled in the neuronal soma, and their egress into the axon, reflecting axonal transport, was inferred by examining the amount of label present in successive axon segments over time. These studies indicated that the three major cytoskeletal proteins are conveyed with overall velocities that are several orders of magnitude lower than those of vesicles and mitochondria. This sluggish rate class was called slow axonal transport ${ }^{25-29}$. Neurofilament proteins and a large fraction of tubulin proteins (microtubule subunits) are conveyed in the slowest form of this transport class, known as 'slow component a' (SCa), moving at rates of approximately $0.2-2 \mathrm{~mm}$ per day. In most peripheral nervous system (PNS) neurons, actin is conveyed a little faster, at rates of approximately 2-4 mm per day, known as 'slow component b' (SCb), though reported rates in CNS neurons are only approximately $0.4 \mathrm{~mm}$ per day ${ }^{26,29}$. Although these studies could detect overall axonal transport, the methods used could not visualize the transported cargo, and mechanistic details remained obscure. With the advent of fluorescent probes including green fluorescent protein (GFP), cytoskeletal structures in a variety of other cell types were visualized by live imaging, revealing a highly dynamic organization ${ }^{30}$. More recent studies, described below, have expanded this concept and ushered in a new era in which super-resolution microscopy and live imaging have played a crucial role.

Although electron microscopy gave an unprecedented view of the cytoskeleton and offered the first clues into its organization, there are two limitations. First, some of the fixatives used in electron microscopy, although invaluable for the visualization of the cytoskeleton, can be harsh, leading to disruption of delicate structures ${ }^{31-34}$ (reviewed in REF. 35). Second, proteins associated with the cytoskeleton cannot be identified easily by this technique. Although immuno-electron microscopy provides a potential solution to the latter problem, the methodology is challenging and idiosyncratic. Fluorescence microscopy, when combined with cytoskeleton-binding probes, offers a number of ways to highlight the cytoskeleton (TABLE 1). However, the axonal cytoskeleton is tightly packed, and it is not easy to discern individual structures owing to the diffraction limit of optical microscopy (approximately $200 \mathrm{~nm}$ ). This issue has now been somewhat resolved by the emergence of optical super-resolution imaging techniques (BOX 2), although these techniques are also subject to fixation artefacts $^{2}$. As described below, these studies have not only clarified the spatial relationships of the various cytoskeletal elements in axons - in some cases revealing new biology - but have also uncovered previously unknown assemblies that could not be appreciated by conventional light microscopy. In addition, our ability to visualize the cytoskeleton by live imaging has been transformative, leading to the demonstration of the transport of neurofilaments as assembled polymers ${ }^{36,37}$ and the motility of microtubule plus-end-tracking proteins ${ }^{38,39}$, for instance. 
Moiré effect

The emergence of a third pattern due to the

superposition of two patterns with distinct frequencies. In microscopy, this effect is exploited in structured illumination microscopy by illuminating the sample with periodic patterns of light and using the resulting Moiré pattern to infer sample details that are beyond the diffraction limit.

\section{Box 2 | Super-resolution optical microscopy techniques}

Several light microscopy techniques allow us to visualize the organization of the cytoskeleton at a resolution that is currently down to a few tens of nanometres. These techniques have also been extended to enable 3D imaging and continue to develop rapidly ${ }^{177-179}$.

When a light microscope is used to acquire a traditional widefield image, all the fluorophores present in a cellular structure emit light at once. In single-molecule-localization microscopy (SMLM, see the figure, part a), only a few fluorophores emit light at any time. In the SMLM modality known as stochastic optical reconstruction microscopy $(\mathrm{STORM})^{180}$, a reducing buffer ensures that most of the organic fluorophores present in an immunolabelled cell enter a long-lasting dark state upon excitation. At any given time, only a few fluorescent molecules are stochastically switched to an active state. In photoactivated localization microscopy (PALM) ${ }^{181}$, fluorophores are photoactivable or photoconvertible fluorescent proteins that are sparsely activated or converted by a low-power violet light, and then imaged and bleached. In both STORM and PALM, light emission from single molecules results in the generation of 'spots' of a size that is determined by diffraction $(200 \mathrm{~nm}$, large red spot). The centre of each isolated spot can be fitted by a 2D Gaussian function, resulting in localization of the spot with $\sim 20 \mathrm{~nm}$ precision (small red dot in inset). The single-molecule coordinates for all fluorophores in the imaged sample are accumulated over a blinking sequence (tens of thousands of frames) to generate an image (the resolution of which is typically $20-30 \mathrm{~nm}$ with current approaches).

Structured illumination microscopy (SIM; see the figure, part b) is based on the illumination of the sample with periodic light patterns (indicated in the schematic by an overlaid grating) that lead to a Moire effect ${ }^{182}$. By acquiring the light emissions that result from 9-15 complementary patterns of excitation, an image can be reconstructed that provides a $2 \mathrm{X}$ gain in resolution (a resolution of $\sim 100 \mathrm{~nm}$ ). Nonlinear variants of SIM can go down to a resolution of $\sim 50 \mathrm{~nm}$ (REF. 183).

Stimulated emission depletion microscopy (STED; see the figure, part c) is a scanning technique based on confocal imaging (left panel). In STED (middle panel), a focused laser scans the sample: this is composed of an excitation beam (inset, blue and pink) and a high-power, donut-shaped depletion beam (inset, blue) that restricts the emission from excited fluorophores to a small, tuneable area (inset, pink) ${ }^{184}$. A single-point detector collects light from this sub-diffractive area, giving a resolution of $\sim 40 \mathrm{~nm}$.

a Widefield image

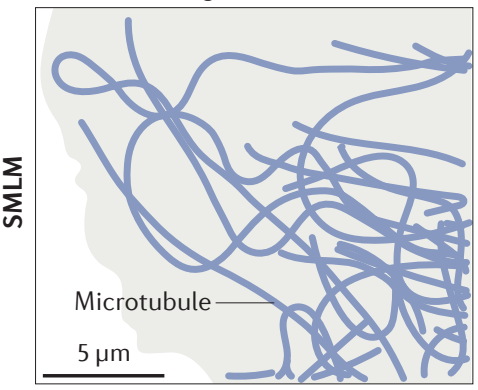

b Widefield image

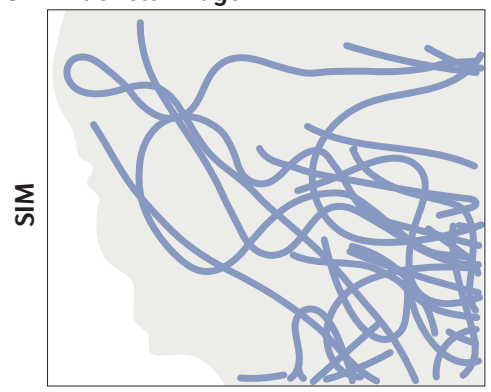

c Confocal image

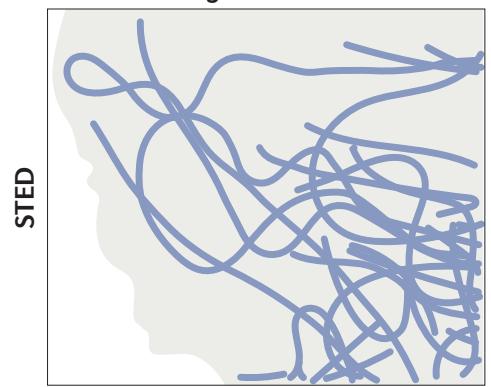

Blinking sequence

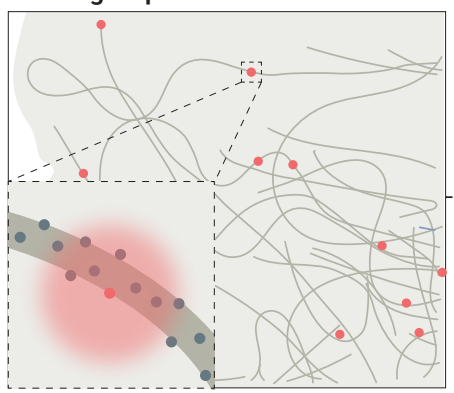

Oriented patterns

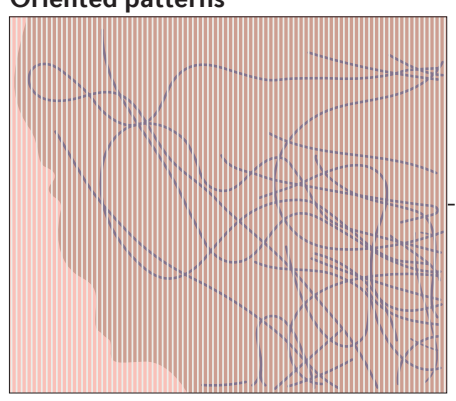

STED scanning

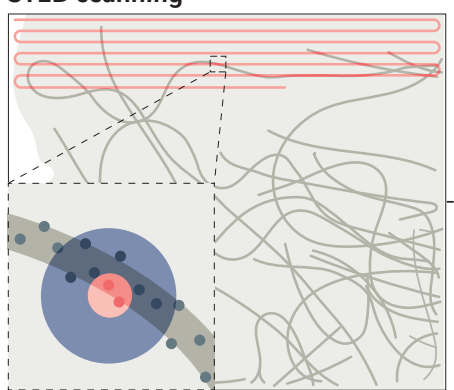

SMLM image

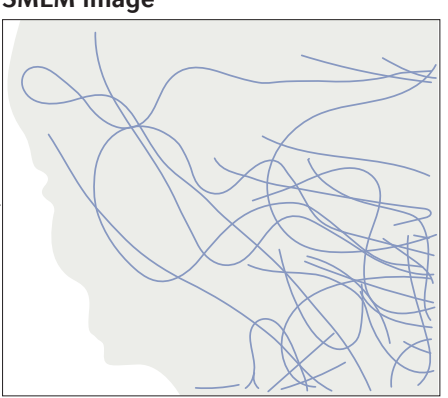

SIM image

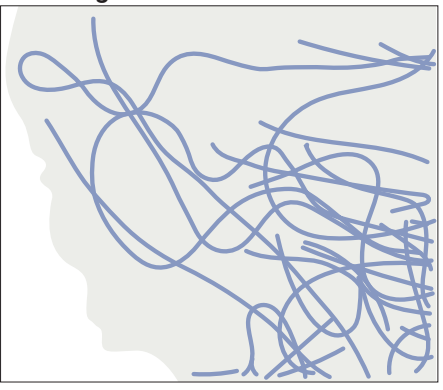

STED image

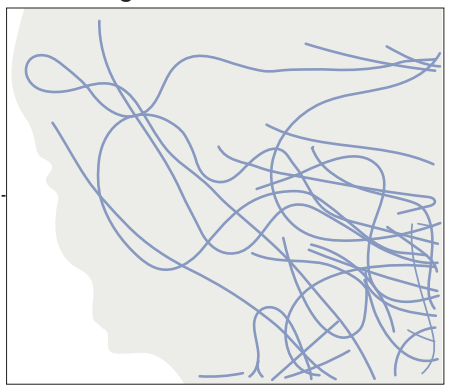




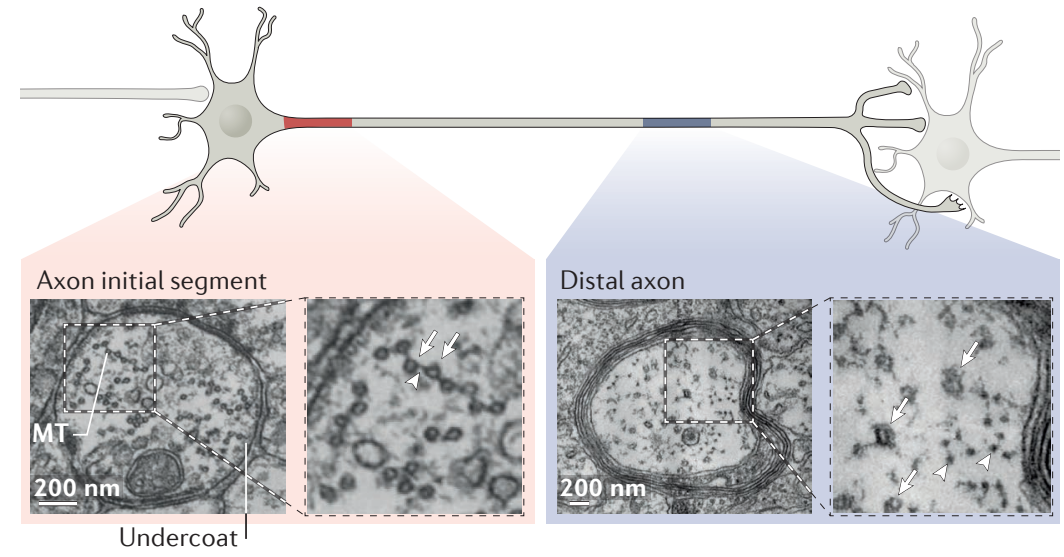

Figure 1 | Ultrastructure of the axon shaft. Classical electron microscopy studies were the first to allow us to visualize the organization of the cytoskeleton within axonal shafts. The schematic depicts the different compartments of a mature neuron, and the electron microscope images illustrate the cytoskeletal ultrastructure in different regions of the axon. The left panels show a thin-section electron micrograph of the axon initial segment from a pyramidal neuron of the rat cerebral cortex and a magnified view of part of this image. On this transverse section, the microtubule fascicles (MT) contain individual microtubules. These appear as beads (arrows in inset) that are connected by cross bridges (arrowhead in inset). The dense undercoat is visible along the plasma membrane. The right panels show a thin-section electron micrograph of a rat optic nerve, specifically the transverse section of a myelinated axon, and a magnified view of part of this image. The microtubules appear as hollow rings (arrows in inset) and neurofilaments as groups of smaller puncta (arrowheads in inset). Left panels adapted with permission from (CPeters et al.J. Cell Biol. 39, 604-619 http://dx.doi.org/10.1083/jcb.39.3.604 (1968) (REF. 14). Right panels adapted with permission from (CPeters and Vaughn. J. Cell Biol. 32, 113-119 http://dx.doi.org/10.1083/jcb.32.1.113 (1967) (REF. 47).

\section{Microtubules in the axon shaft}

Organization of axonal microtubules. As first revealed by electron microscopy, microtubules within the axon are uniformly oriented with their plus ends directed towards the axon tip, whereas dendrites contain a mixture of plus-end-out and minus-end-out microtubules $^{40-43}$. More recently, axonal microtubule polarity was confirmed in cultured neurons and in vivo by tracking growing microtubules with fluorescent microtubule end-binding proteins (EBs) such as EB1 (also known as microtubule-associated protein RP/EB family member 1 (MAPRE1)) and EB3 (also known as MAPRE3) $)^{38,39,44,45}$. Notably, this revealed that microtubule polarity changes progressively over development from $80 \%$ plus-end-out in undifferentiated neurites (BOX 3) to $100 \%$ plus-endout after axon specification ${ }^{39}$.

In vertebrate axons, microtubules are densely packed, with an average of ten microtubules per square micrometre in cross sections of large-diameter axons and up to 100 per square micrometre in smaller ones ${ }^{46,47}$. Owing to their density and bundling, determining the lengths of axonal microtubules has been difficult. Using serial-section electron microscopy, the reported lengths of microtubules in vertebrates were $4 \mu \mathrm{m}$ on average in cultured rat sympathetic neurons ${ }^{48}$ but much longer when measured in vivo (including $100 \mu \mathrm{m}$ in rat sensory axons $\mathrm{s}^{49}, 400 \mu \mathrm{m}$ in frog olfactory axons $\mathrm{s}^{50,51}$ and up to $750 \mu \mathrm{m}$ along the mouse saphenous nerve ${ }^{52}$ ). The sparsity of axonal microtubules in Caenorhabditis elegans DA9 motor neurons recently allowed an optical method to be used to determine their microtubule organization and length. Using transgenic worms engineered to express tubulin-GFP, a recent study visualized 'steps' in fluorescence profiles along axons that correspond to the microtubule extremities ${ }^{53}$. This revealed that the average microtubule length varied between $3.5 \mu \mathrm{m}$ in L2-stage larvae and $7 \mu \mathrm{m}$ in adult worms ${ }^{53}$, in line with previous estimates from electron microscopy $\left(10-20 \mu \mathrm{m}\right.$ in touch receptor neurons $\left.{ }^{54}\right)$. These lengths are significantly shorter than those of mammalian neurons, where the higher density and longer length of microtubules preclude the use of this optical approach. Refinements in super-resolution techniques could help in this regard: for instance, single-particle tracking of retrogradely transported cargoes - by using quantum dots conjugated with nerve growth factor molecules results in nanoscale trajectories that make it possible to discriminate between individual microtubules within axonal bundles ${ }^{55}$. New, smaller probes also allow the labelling and super-resolution imaging of individual microtubules, which are normally densely packed in neuronal processes ${ }^{56}$.

As described above, microtubules have a unique organization at the AIS, forming tight bundles connected by electron-dense crosslinkers ${ }^{13}$ (FICS 1,2a). Although the identity of the crosslinkers is still unknown, a recently identified protein, tripartite motif-containing protein 46 (TRIM46), may be a candidate. Identified as the target of autoantibodies derived from patients with paraneoplastic neurological syndrome, TRIM46 is enriched along microtubules in the proximal AIS ${ }^{57}$. By use of a combination of super-resolution and live-cell imaging, TRIM46 was shown to drive the establishment of uniformly oriented microtubules at the axon entrance and also to generate fascicles of microtubules when overexpressed in HeLa cells ${ }^{58}$. The specific organization of AIS microtubules has long been thought to have a role in regulating cargo entry into the axon ${ }^{59}$, and, interestingly, polarized trafficking is disrupted in TRIM46-deficient neurons ${ }^{58}$. Another microtubule-associated protein, microtubule crosslinking factor 1 (MTCL1), was recently shown to be enriched at the AIS of cerebellar Purkinje cells and to help in AIS maturation and maintenance ${ }^{60}$. Finally, microtubule-associated EBs provide a molecular link between the submembrane actin-spectrin complex (see below) and the deeper AIS microtubule fascicles ${ }^{11}$. Specifically, AIS microtubules contain a high density of non-hydrolysed GTP-tubulin clusters called GTP islands. These GTP islands can help recruit EBs to the AIS, as shown by electron and super-resolution microscopy ${ }^{61,62}$. EBs can bind to the AIS scaffold protein ankyrin- $\mathrm{G}^{63,64}$, which is itself bound to $\beta I V$-spectrin (also known as SPTBN4), which interacts with $\operatorname{actin}^{65}$ (FIG. 2a).

Dynamics of axonal microtubules. Once the axon is specified, it grows at a sustained speed (between 1 and $100 \mu \mathrm{m}$ per hour), and there is a long-standing debate on how microtubules are supplied at a high rate to support this elongation. Issues include where the microtubules are nucleated - the process by which new microtubules start to polymerize - and how they are eventually 
Table 1 | Probes that label the axonal actin cytoskeleton and actin-binding proteins

\begin{tabular}{|c|c|c|}
\hline Probe & Imaging technique & Refs \\
\hline \multicolumn{3}{|c|}{ Probes used to label the submembrane periodic scaffold } \\
\hline \multirow[t]{2}{*}{ Phalloidin } & STORM & $65,127,131,132,138$ \\
\hline & STED & 136,137 \\
\hline \multirow[t]{3}{*}{ SiR-actin } & STED* & $130,131,133$ \\
\hline & STED & 140 \\
\hline & SIM & 135 \\
\hline Anti- $\alpha$-adducin antibody & STORM & 127,139 \\
\hline \multirow[t]{2}{*}{ Anti- $\beta$ II-spectrin antibody } & STORM & $\begin{array}{r}65,127,132,134 \\
138,139,172\end{array}$ \\
\hline & STED & 136 \\
\hline ßII-Spectrin-mMaple3 & PALM $^{*}$ & 139 \\
\hline BII-Spectrin-GFP & Epifluorescence* & 139 \\
\hline Anti- $\beta$ IV-spectrin antibody & STORM & $65,127,131,132$ \\
\hline \multicolumn{3}{|l|}{ Probes used to label actin waves } \\
\hline \multirow[t]{2}{*}{ Phalloidin } & Epifluorescence & 149 \\
\hline & SIM & 153 \\
\hline GFP- $\beta$-actin; mRFP- $\beta$-actin & Epifluorescence* & 155 \\
\hline paGFP- $\beta$-actin or dendra- $\beta$-actin & $\begin{array}{l}\text { Photoactivation and/or } \\
\text { conversion* }\end{array}$ & 152 \\
\hline F-tractin-mCherry & Epifluorescence* & 153 \\
\hline LYN-mCherry (membrane marker) & Epifluorescence* & 153 \\
\hline THY1-YFP (neuronal marker) & Epifluorescence* & 155 \\
\hline Anti-cortactin antibody & Epifluorescence & 152 \\
\hline Anti-shootin antibody & Epifluorescence & 152 \\
\hline \multicolumn{3}{|c|}{ Probes used to label actin trails and hot spots } \\
\hline GFP-UTRN-CH & Epifluorescence* & 148 \\
\hline LifeAct-mTurquoise & Epifluorescence* & 148 \\
\hline
\end{tabular}

$\mathrm{CH}$, calponin homology domain; GFP, green fluorescent protein; LYN, tyrosine-protein kinase Lyn; mRFP, monomeric red fluorescent protein; PALM, photoactivated localization microscopy; SiR, silicon-rhodamine; SIM, structured illumination microscopy; STED, stimulated emission depletion microscopy; STORM, stochastic optical reconstruction microscopy; THY1, Thy-1 membrane glycoprotein; UTRN, utrophin; YFP, yellow fluorescent protein. *indicates techniques that were used for live imaging.

Centrosome

An organelle that nucleates

and controls the organization of microtubules and regulates cell-cycle progression. transported into the growing parts of the axon. One view is that microtubules are nucleated at the centrosome in the cell body and then severed by the enzymes katanin and spastin to generate smaller fragments. According to this view, the fragments are then transported into the axon, where they integrate into longer microtubules and elongate axons ${ }^{66,67}$ (reviewed in REF. 68). However, laser ablation of the centrosome in neurons suggests that it is dispensable for axon growth ${ }^{69}$. Moreover, the free minus ends of most neuronal microtubules are not attached to the centrosome ${ }^{48}$. Genetic evidence in Drosophila melanogaster neurons also suggests that axonal growth is independent of centrosome nucleation activity ${ }^{70}$. Finally, the microtubule nucleation machinery at the centrosome is lost during neuronal maturation ${ }^{69,71}$, and super-resolution microscopy reveals that microtubules lose their radial organization around the centrosome soon after maturation ${ }^{72}$. This raises the question of what the alternative nucleation site for axonal microtubules might be. In non-neuronal cells, microtubules can be nucleated from isolated $\gamma$-tubulin clusters, the Golgi apparatus, plasma membrane or other microtubules ${ }^{73}$. Golgi-nucleated microtubules have been described in dendrites of $D$. melanogaster neurons ${ }^{74,75}$, but it is unclear whether they also exist in axons. A nucleation mechanism that involves microtubule side-branching from $\gamma$-tubulin-augmin complexes has been recently proposed as a source of axonal microtubules ${ }^{76}$ (FIG. 2a). As an alternative to nucleation, severing of existing microtubules by katanin and/or spastin along the axon, followed by growth of the resulting fragments, could increase and renew the axonal microtubule pool. An appeal of this mechanism is that it would intrinsically conserve the uniform plus-end-out orientation of the resulting network ${ }^{77}$.

Even the highest estimates of microtubule length are far shorter than the total length of a typical axon, and axons must therefore contain a succession of overlapping microtubules throughout their length. The plus ends of these microtubules are usually in a state of dynamic instability, alternating between phases of growth (polymerization), pauses at a constant length and catastrophe (fast depolymerization $)^{78}$, whereas the non-centrosomebound minus end is bound to stabilizing minus-end proteins ${ }^{79,80}$. Several minus-end-anchoring proteins in the axon have recently been identified. In C. elegans axons, PTRN-1 (the homologue of the D. melanogaster minus-end-binding protein patronin ${ }^{81}$ ) localizes as small puncta along the axons and stabilizes microtubules ${ }^{82,83}$, as shown by live-cell imaging. In mammalian neurons, calmodulin-regulated spectrin-associated protein 2 (CAMSAP2) stabilizes microtubules by binding to their minus ends and is concentrated at the axon hillock and as puncta along the $\operatorname{axon}^{72}$ (FIG. 2a). Other, yet unknown minus-end-anchoring proteins are likely to be present in neurons, particularly along axons ${ }^{79}$.

Although microtubules are generally more stable in neurons than in non-neuronal cells, their stability depends on the maturation stage and cellular localization $^{84}$. Axonal microtubules are more stable than their dendritic counterparts ${ }^{85}$, and individual microtubules are known to have both stable and unstable domains along their length ${ }^{86,87}$. A current challenge is to visualize not only the growing ends of axonal microtubules (by using fluorescent EBs) but also the stable segments that represent the vast majority of axonal microtubules ${ }^{77}$. A recent study cut the microtubules at a precise point with laser microsurgery and then observed the growth of newly created microtubule ends labelled by fluorescent EBs, allowing the visualization of stable microtubules in axons by their subsequent growth ${ }^{39}$. However, this method does not reveal microtubules that do not grow after being cut. Here again, super-resolution microscopy with optimized probes ${ }^{56}$ may provide answers in the near future by comprehensively mapping the organization of the axonal microtubule network.

Chemical modifications to tubulin are important for regulating microtubule structure and function. In addition to the hydrolysis of $\beta$-tubulin-bound GTP to GDP, tubulin undergoes several post-translational 


\section{Box 3 | Stereotypical development of neurons in culture}

Hippocampal neurons in culture are a widely used cellular model, and their development is divided into five stages ${ }^{185}$. Axon formation starts with neuritogenesis the emergence of multiple processes from a single cell body. Shortly after cell attachment to the substrate, the broad, fanned-out actin-rich processes (known as lamellipodia; see the figure, stage 1) transition into thin, spiky projections (filopodia (not shown)). As the filopodia emerge, microtubules invade the nascent projections, leading to neurite formation (stage 2) ${ }^{150,186}$ (reviewed in REF. 187). At this stage, the neurites are $10-15 \mu \mathrm{m}$ long and undifferentiated. A combination of intrinsic factors and external cues then specifies one neurite to become the axon ${ }^{185,188,189}$ (for more details on mechanisms of axon specification, see recent reviews ${ }^{190-192}$ ). The growing axon is supported by a selective flow of vesicles and cytoplasmic material ${ }^{193}$, and axon specification depends on concomitant actin destabilization and microtubule stabilization in the nascent axon ${ }^{194,195}$ that allows its fast growth (stage 3). The tip of the growing axon - the growth cone - provides a canonical example of motility that is driven by a coupling between a retrograde flow of actin and selective stabilization of microtubule growth (see recent reviews on this subject ${ }^{196-198}$ and see a recent study ${ }^{199}$ using super-resolution microscopy in living cells to delineate the interplay between actin and vesicle endocytosis during growth-cone advance).

At the end of stage 3, the axon initial segment (AIS) starts to assemble ${ }^{200,201}$. During days 4-7 in culture (stage 4), the axon continues to grow. Collateral branches often emerge from established axons, and this process also requires cooperation between the actin and microtubule cytoskeleton (recently reviewed in REFS 160,202). Synapses start to form when axons contact neighbouring neurons. After 7 days in culture (stage 5), the dendritic arborization grows and becomes more complex, and the axon continues to grow and contact numerous other neurons $\mathrm{s}^{203}$.

Stage 1 (0-12 hours)
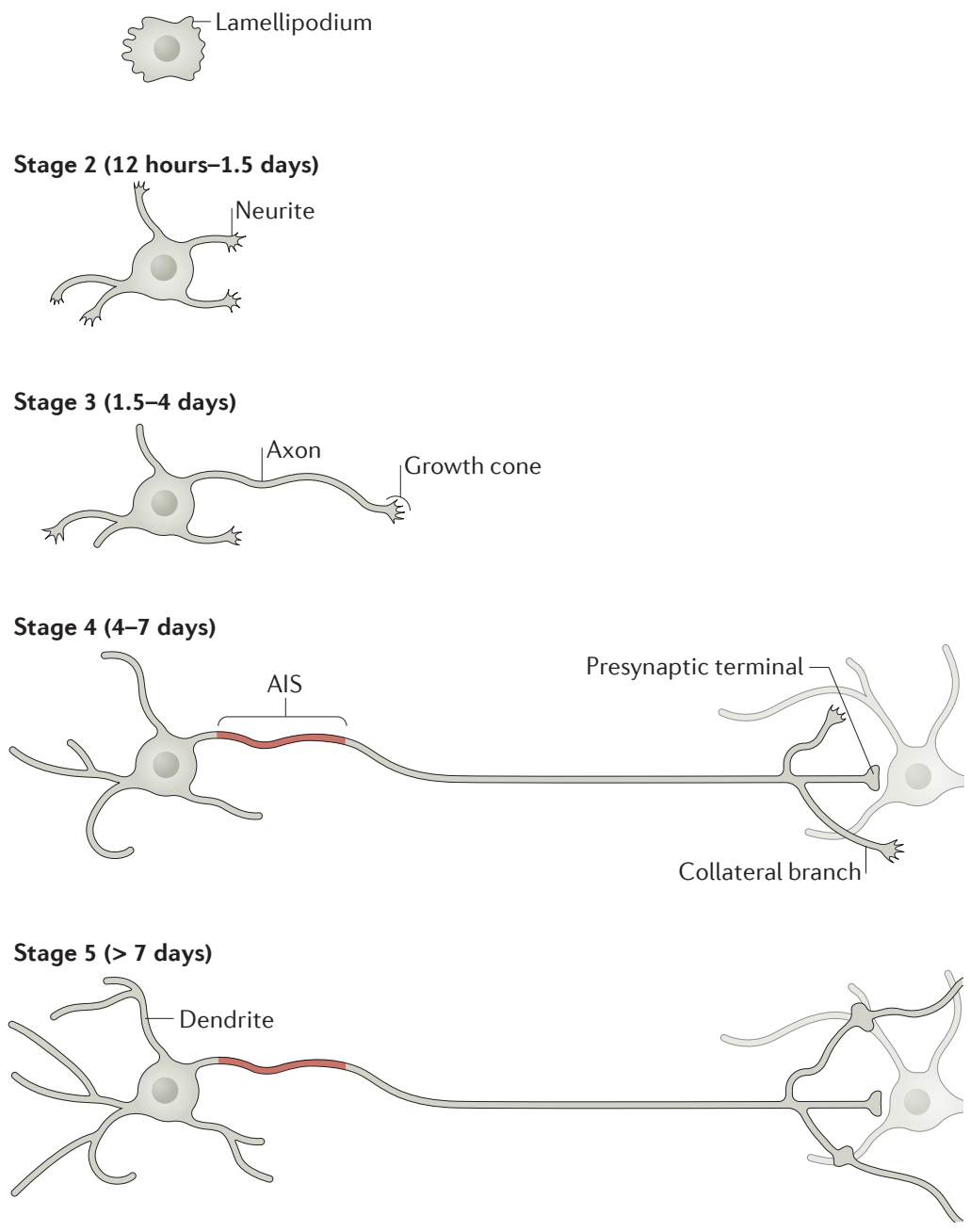

modifications (PTMs) - including detyrosination, polyglutamylation and acetylation - that accumulate on more stable microtubules ${ }^{88}$. A newly characterized PTM, polyamination, may be responsible for the maintenance of a stable, cold-resistant microtubule population in axons ${ }^{84,89}$. PTMs can alter the affinity of motors and microtubule-associated proteins $s^{90,91}$ and are also likely to regulate the cytoskeletal network architecture by modifying the structural properties of microtubules ${ }^{92}$. AIS microtubules are rich in PTMs, although the role of these modifications in the selective recruitment of axonal cargoes is unclear ${ }^{93-95}$. The advent of new tools to visualize specific tubulin modifications in living cells ${ }^{96,97}$, as well as techniques to locally perturb microtubules ${ }^{98}$, will undoubtedly help us to dissect the extent and role of PTMs in the axonal architecture.

Axonal transport of tubulin. As noted above, pulsechase radiolabelling studies showed that most tubulin is transported in the SCa, whereas a smaller fraction is conveyed in the slightly faster $\mathrm{SCb}^{28}$. Although the latter fraction of tubulin is largely soluble in a cold, lowsalt detergent (Triton-X 100) - indicating that it may exist in a non-polymeric form - approximately half of the slower fraction in SCa is insoluble, suggesting compositional differences in the two transport components ${ }^{99}$; however, the importance of these differences has been unclear. Studies also suggest that only a small fraction of tubulin in axons is transported ${ }^{100}$, which is relevant for the interpretation of studies that use fluorescent markers in cultured neurons. A number of studies in the 1980s and 1990s directly visualized the dynamics of fluorescent tubulin in axons. The consensus was that most microtubules in axons are stationary (reviewed in REF. 28). However, other studies showed that taxol-stabilized tubulin fragments injected into the squid axon can move with an anterograde bias and revealed the presence of short, motile microtubules at branch points of cultured neurons ${ }^{101,102}$, suggesting that axonal microtubules can move.

In squid axons, injection of fluorescent tubulin resulted in the slow, anterograde advance of the bolus, at overall rates that were consistent with slow axonal transport ${ }^{103,104}$. Addition of the microtubuledepolymerizing drug nocodazole in this system did not impair this biased motion, indicating that tubulin may be able to move in an unpolymerized state ${ }^{103}$. In 2002 , by use of a photobleaching-based paradigm, it was shown that linear structures containing fluorescent tubulin (presumably short microtubules) moved rapidly in cultured rat sympathetic neurons, with a significant overall anterograde bias ${ }^{105}$. However, the movement was very infrequent (approximately one event every 4 minutes) when compared with that of vesicle transport, and the moving structures spent about half of their time pausing (reviewed in REF. 106). Similar dynamics had also been seen for neurofilament transport, leading to the concept that the overall slow movement seen in the radiolabelling studies is a summation of rapid movement interrupted by long pauses (the 'stop and go' model, see below). 


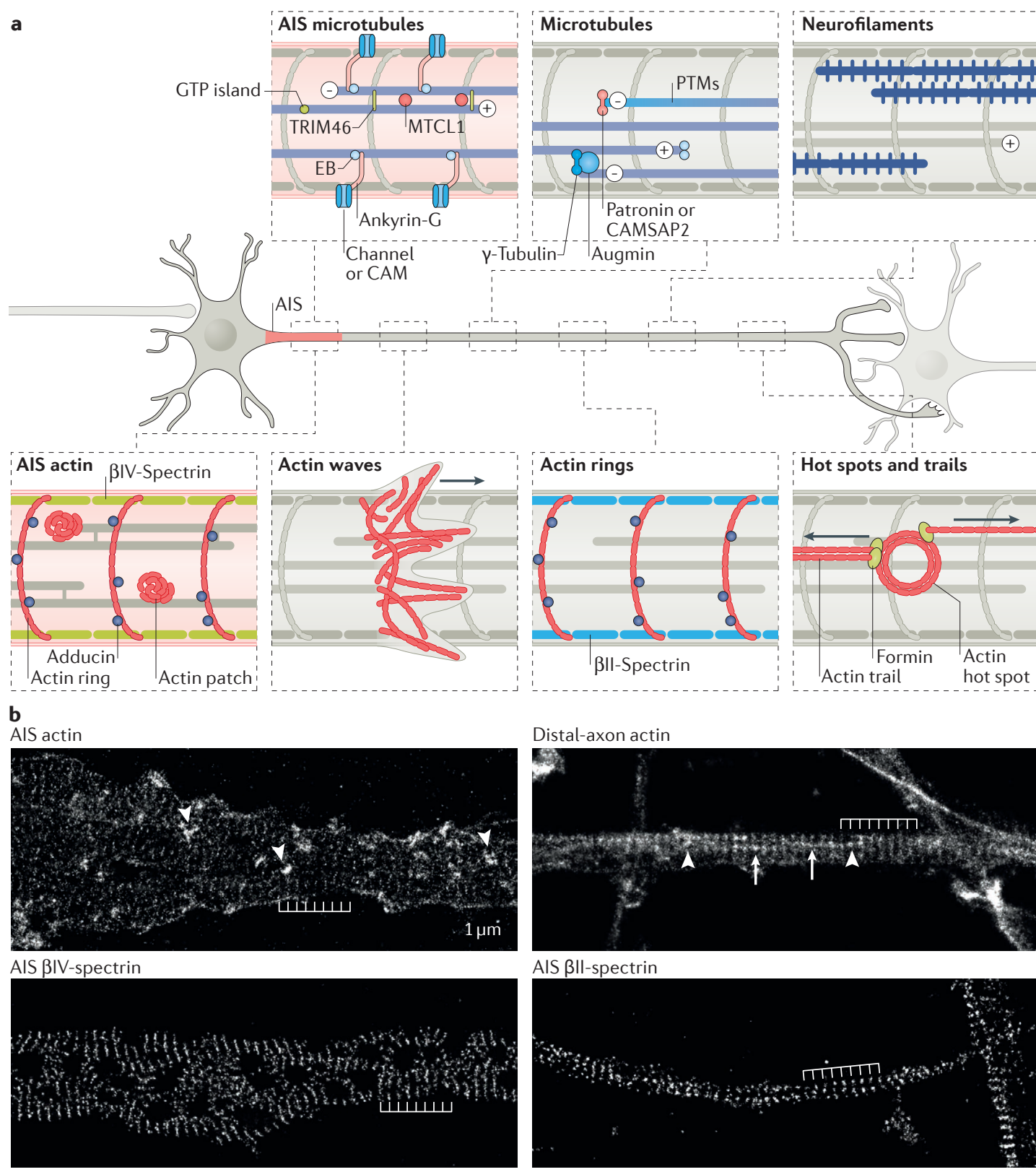

Figure 2 | The cytoskeleton of the axon shaft. a |The axon shaft is divided into the axon initial segment (AIS) and the distal axon shaft. In the AIS, microtubules (top left panel, blue) are oriented uniformly with the minus end (-) towards the cell body and the plus end (+) towards the distal axon. They form AIS-specific fascicles enriched in GTP islands and the associated proteins tripartite motif-containing protein 46 (TRIM46) and microtubule crosslinking factor 1 (MTCL1). End-binding proteins (EBs) link microtubules to ankyrin-G, which in turn binds to spectrin and anchors membrane proteins (channels and cell adhesion molecules (CAMs). Microtubules in the distal axon (top centre panel) are also uniformly oriented and enriched in post-translational modifications (PTMs). They are anchored at the minus end by proteins such as patronin, calmodulin-regulated spectrin-associated protein 2 (CAMSAP2) and the $\gamma$-tubulin-augmin complex and are decorated with EBs at the growing plus end. Neurofilaments (top right panel, dark blue) are stable assemblies that fill the intra-axonal space. AIS actin (bottom left panel, red) is organized as submembrane rings enriched in adducin that are spaced every $190 \mathrm{~nm}$ by $\beta$ IV-spectrin, as well as actin patches inside the axon. In younger neurons, actin waves (bottom centre panel) propagate along the axon shaft. In the distal axon, the actin rings are also spaced every $190 \mathrm{~nm}$, but by $\beta$ II-spectrin. Dynamic actin hot spots (bottom right panel) nucleate actin trails formed by fast,

formin-mediated polymerization. $\mathbf{b}$ | Stochastic optical reconstruction microscopy (STORM) images of actin and spectrin in the AIS and distal axon. Actin in the AIS (upper left panel) organizes as $190 \mathrm{~nm}$ periodic rings (comb) and clusters (arrowheads). In the distal axon (upper right panel), actin rings are seen (comb) along with long actin polymers (arrows) and focal accumulations (arrowheads) that likely represent actin trails and hot spots ${ }^{146}$. Spectrins connect the actin rings and show the same $190 \mathrm{~nm}$ periodicity (indicated by the combs): $\beta$ IV-spectrin in the AIS (lower left panel) and $\beta$ II-spectrin along the distal axon (lower right panel). Left panels and lower right panel in part $\mathbf{b}$ are adapted with permission from REF. 65, upper right panel in part b is adapted with permission from @ Ganguly et al. J. Cell Biol. 210, 401-417 http://dx.doi. org/10.1083/jcb.201506110 (2015) (REF. 148). 
What are the mechanisms underlying this transport? Using live-cell imaging and fluorescent probes, more recent studies suggest that dynein motors are involved in both anterograde and retrograde transport of microtubules ${ }^{107,108}$, whereas super-resolution microscopy has started to unravel the elusive structure of slow-transport cargoes ${ }^{109}$. Microtubule movement in other cell types is well established, providing a precedent ${ }^{110,111}$. However, further studies are needed to clarify the role of soluble tubulin pools in this transport, if any, and to characterize the short mobile microtubules.

\section{Neurofilaments in the axon shaft}

Organization of neurofilaments. Neurofilaments are heteropolymers composed of subunits of low, middle and high molecular weight, along with one of the two recently discovered forms of intermediate filament protein, $\alpha$-internexin (in the CNS) or peripherin (in the PNS) and are organized as extensive parallel networks that fill the axoplasm (BOX 1; FIG. 1). In classical electron microscopy studies using the freeze-etching technique, neurofilaments appeared to be interconnected with inter-filament cross bridges that are approximately $3-5 \mathrm{~nm}$ in diameter ${ }^{112}$. Although the function of these cross bridges is not clear, they have been proposed to help to maintain the integrity and density of the neurofilament network and to keep the neurofilament network anchored to the plasma membrane and microtubules ${ }^{112}$ (FIG. 2).

The assembly of neurofilaments starts with heterodimerization of two neurofilament proteins with their $\mathrm{N}$-terminals aligned. These dimers then form a staggered tetramer with the N-terminals of the assembled dimer on each side, resulting in a nonpolar assembly. Approximately eight of these tetramers are assembled laterally to form unit-length filaments, which then anneal end to end to form neurofilaments ${ }^{113}$ (BOX 1). Although neurofilaments are stable polymers with long half-lives, recent live imaging of fluorescently tagged neurofilaments revealed a dynamic process where neurofilament severing and annealing are common ${ }^{114}$. The mechanisms underlying this dynamic behaviour are largely unknown, and the precise relationship between neurofilaments and other cytoskeletal structures have not yet been explored by super-resolution microscopy (although a recent study used structured illumination microscopy (SIM) to examine intermediate filaments in glial cells ${ }^{115}$ ).

Axonal transport of neurofilaments. The slow axonal transport (SCa) of neurofilament proteins has been well documented by classic radiolabelling studies ${ }^{25,116-118}$; however, the form that is transported (monomer, oligomer or polymer) was debated for a long time $e^{119,120}$. Because neurofilaments are highly abundant in axons, the motility of individual fluorescently tagged neurofilaments could not be easily visualized. Taking advantage of the discontinuous neurofilament network in axons of cultured sympathetic neurons, live imaging studies have now unequivocally demonstrated the movement of neurofilament polymers ${ }^{36,37,121}$. Surprisingly, however, the movement of individual neurofilament polymers was rapid, resembling the velocities of fast transport cargoes. Unlike fast cargoes, neurofilament movement was very infrequent and the cargoes paused for prolonged periods during transit. This led to a 'stop and go' model for slow transport, which proposes that individual cargoes move rapidly but intermittently, leading to a slow overall movement of the population (reviewed in REF. 106). More recent studies suggest a model in which larger neurofilaments are largely stationary but are severed into smaller polymers that can be transported ${ }^{114}$. Conventional kinesins and dynein are involved in neurofilament transport ${ }^{122}$, although the molecular mechanisms underlying the intermittent transport are still unclear.

\section{Actin in the axon shaft}

Organization of actin. Early electron microscopy studies showed a layer of sub-plasmalemmal actin along axon shafts $^{123}$, but intra-axonal actin was difficult to discern owing to the dense packing of cytoskeletal polymers and organelles within the lumen ${ }^{6,7}$. However, phalloidin staining of axoplasm extruded from squid giant axon showed extensive deep actin filaments ${ }^{124}$. 'Touch preparations' - in which a carbon-coated electron microscopy grid is touched against the surface of axoplasm to transfer a thin layer of the sample - suggested that actin filaments in axons were rather short, averaging only approximately $0.5-1 \mu \mathrm{m}$ in length, and were in close apposition with microtubules ${ }^{125}$. However, such touch preparations are inherently disruptive and need to be interpreted with caution ${ }^{125}$. Experiments where skeletal myosin subfragment 1 was used to coat the actin filaments in a characteristic arrowhead pattern suggested that the polarity orientation of axonal actin filaments was mixed ${ }^{125}$. Phalloidin staining of axons in cultured neurons showed a patchy distribution, thought to reflect a combination of sub-plasmalemmal and deep actin ${ }^{126}$. Thus, until recently, the prevailing model of actin organization suggested that axon shafts have a coat of actin underneath the plasma membrane as well as deeper, short actin filaments with mixed polarity ${ }^{35}$. However, new information from super-resolution microscopy and live imaging has substantially revised this view.

In 2013, stochastic optical reconstruction microscopy (STORM, see BOX 2) was used to re-evaluate axonal actin organization, using the classical probe phalloi$\operatorname{din}^{127}$. Surprisingly, the patchy, apparently unremarkable actin seen only by routine light microscopy was shown to be composed of a periodic cytoskeletal assembly that can be seen by sub-diffraction microscopy techniques. Specifically, axons contain circumferential rings of actin that wrap underneath the plasma membrane and are spaced at approximately $190 \mathrm{~nm}$ (REF. 127 ) (FIG. 2b). Actin rings are connected by tetramers of spectrin, composed of $\beta I I$-spectrin (also known as SPTBN1) and a stillunknown $\alpha$-spectrin subunit, that are also approximately $190 \mathrm{~nm}$ long ${ }^{128,129}$. This periodic organization of actin was also seen in living neurons by using stimulated emission depletion microscopy (STED, see BOX 2) ${ }^{130,131}$. Moreover, the periodic actin-spectrin undercoat has been shown to be present along myelinated axons ${ }^{131,132}$ and to be conserved in a variety of neuronal types and organisms ${ }^{133-135}$. 
Fluorescence recovery after photobleaching

A method used to measure the diffusion or transport of molecules. It requires tagging of the molecule of interest with a fluorescent marker, photobleaching of the label with a pulse of laser light and a subsequent measure of the rate of fluorescence recovery into the bleached area as other labelled molecules move into it.
It has been proposed that this actin-spectrin assembly could be an intrinsic property of cytoskeletal organization in thin processes, because similar periodicity in dendritic spine necks and the fine processes of glial have been reported ${ }^{133,134,136,137}$. Recently, a 2D polygonal lattice structure - resembling the erythrocyte membrane skeleton - was reported in larger compartments such as the cell body and large dendrites ${ }^{138}$.

The actin-spectrin periodic complex appears to be immobile and stable, as shown by $\beta \mathrm{II}$-spectrin fluorescence recovery after photobleaching and live-cell photoactivated localization microscopy (PALM, see BOX 2) experiments, and is also partially resistant to actin and microtubule depolymerization ${ }^{139}$. During development, actin rings first appear along the most proximal axon segment and have been proposed to 'propagate' along the shaft as the axon grows, although the rings themselves do not appear to move ${ }^{139}$. Mechanisms underlying the initial assembly of the rings and their progression along the shaft are unclear, but slow axonal transport of ring components may play a role (see below). Actin rings also contain adducin, a capping protein that binds to and stabilizes the ends of short actin filaments ${ }^{127,140}$. For this reason, it is thought that actin rings are composed of numerous short and stable actin filaments ${ }^{141}$, although the actin rings have not yet been seen by electron microscopy. Interestingly, an absence of adducin increases the diameter of the actin rings, presumably because individual short filaments forming the ring can no longer be capped ${ }^{140}$.
Actin rings are present along the entire axon, including the AIS; however, the $\beta$-spectrin subunits in the AIS and the more distal axon are different ${ }^{65,127}$. As the AIS is established, the $\beta I I-$ spectrin in this region is replaced by $\beta I V$-spectrin ${ }^{139}$. This switch contributes to the establishment of segregated submembrane scaffolds along the axon: $\beta I V$-spectrinankyrin-G scaffolds in the AIS and $\beta I I-$ spectrin-ankyrin-B scaffolds in the distal axon ${ }^{142}$; however, the relevance of this differential assembly is still unknown. In addition to actin rings, the AIS contains longitudinal actin filaments and actin clusters ${ }^{131,143}$. Some of these actin clusters are likely to correspond to postsynaptic sites, as the AIS is innervated by GABAergic neurons ${ }^{131}$. However, there are larger (approximately $1 \mu \mathrm{m}$ in diameter) 'actin patches' in the AIS ${ }^{143,144}$, and these may play a role in sorting vesicular transport by capturing myosin-bearing vesicles ${ }^{145-147}$.

Although it was known that axons have both sub-plasmalemmal and deep actin ${ }^{125}$, the characteristics of the latter (the filament length, dynamics and polarity, for example) were unclear. A recent study examined axonal actin by using filament-selective probes and low-light live imaging ${ }^{148}$ (TABLE 2). Deep axonal actin was shown to be surprisingly dynamic: distributed along the length of the axon were focal actin 'hot spots', where actin continuously polymerized and depolymerized. Additionally, elongating actin polymers were seen along the long axis (these averaged approximately $9 \mu \mathrm{m}$ in length, with the longest ones being up to $40 \mu \mathrm{m}$ in length), extending in both anterograde and retrograde directions. These were termed 'actin trails' (FIG. 2b). The actin trails often seemed

Table 2 | Components of axonal actin assemblies and actin-binding proteins

\begin{tabular}{|c|c|c|}
\hline Protein & Organization and/or function & Refs \\
\hline \multicolumn{3}{|c|}{ Components of the submembrane periodic scaffold } \\
\hline a-Adducin & $\begin{array}{l}\text { Present at actin rings. Involved in capping of actin filaments and } \\
\text { regulation of axon diameter }\end{array}$ & $127,139,140$ \\
\hline$\beta I I-S p e c t r i n$ & $\begin{array}{l}\text { Links actin rings in the distal axon. Involved in regulation of scaffold } \\
\text { formation }\end{array}$ & $65,127,134,139$ \\
\hline$\beta I V-S p e c t r i n$ & Links actin rings at the AIS & $65,127,139$ \\
\hline Ankyrin-B & Bound to $\beta I I-$ spectrin in the distal axon & 127 \\
\hline Ankyrin-G & Bound to $\beta I V$-spectrin at the AIS & $65,127,139$ \\
\hline Nav channels & Anchored to ankyrin-G at the AIS & 65,127 \\
\hline Kv1.2 & Associated with the actin rings at the AIS & 132 \\
\hline Neurofascin & Anchored to ankyrin-G at the AIS & 65,131 \\
\hline \multicolumn{3}{|l|}{ Components of actin waves } \\
\hline Doublecortin & $\begin{array}{l}\text { Controls the frequency of waves and promotes axon specification } \\
\text { and branching }\end{array}$ & 151 \\
\hline Shootin1 & Couples actin filaments to the substrate & 152 \\
\hline RAC1 & Induces actin wave & 153 \\
\hline $\begin{array}{l}\text { ARP2/3, CDC42, RAP1B and } \\
\text { cofilin, Lim kinase and slingshot }\end{array}$ & $\begin{array}{l}\text { Function not explored in actin waves but likely to be involved in the } \\
\text { movement of waves }\end{array}$ & 153,155 \\
\hline Ezrin, GAP43 and cortactin & $\begin{array}{l}\text { Function not explored in actin waves but likely to be involved in } \\
\text { actin dynamics }\end{array}$ & 149 \\
\hline \multicolumn{3}{|c|}{ Components of actin trails and hot spots } \\
\hline
\end{tabular}

AIS, axon initial segment; ARP2/3, actin-related protein 2/3 complex; CDC42, cell division control protein 42 homologue; GAP43, growth associated protein 43; Kv1.2, voltage-gated potassium channel KCNA2; Nav channels, voltage-gated sodium channels; RAC1, Ras-related C3 botulinum toxin substrate 1; RAP1B, Ras-related protein 1B. 
to arise from regions of hot spots, suggesting a scenario in which actin filament polymerization at hot spots created the nidus of assembly that initiated polymer elongation. The rate of elongation was rapid (approximately $1 \mu \mathrm{m} \mathrm{s}^{-1}$ ) and depended on linear polymer growth mediated by formins and not on the actin-branching complex ARP $2 / 3$ (REF. 148). Collectively, the data indicate that axon shafts have two cytoskeletal networks: stable sub-plasmalemmal rings, composed of circumferential actin-spectrin assemblies and actin trails, a dynamic deep actin network consisting of focal actin hot spots and elongating filaments meandering along the shaft.

Besides rings and trails, developing axons also have other intriguing actin assemblies. Actin 'waves' are growth-cone-like structures that periodically emerge at the base of the axon, travelling along its length, up to the axon tip ${ }^{149-154}$ (FIG. 2b). Best studied in cultured neurons, actin waves are present in all neurites before differentiation but are more frequent in the nascent axon ${ }^{155}$. These waves disappear as axons mature and make contacts with other neurons (reviewed in REF. 156). Similar waves of actin have also been described in other cell types such as fibroblasts, neutrophils, keratinocytes and Dictyostelium discoideum, where they are called travelling waves or t-waves ${ }^{157}$. Distal-axon 'actin patches' that may be similar to the ones found in the AIS have also been described in a variety of neurons (reviewed in REF. 158). Unlike actin waves, the patches are non-protrusive, focal accumulations within the shaft. Available data support the notion that actin patches in distal axons are involved in the emergence of axonal filopodia and branches ${ }^{159,160}$.

Axonal transport of actin. Slow axonal transport of actin has been demonstrated in many different species by pulsechase radiolabelling studies ${ }^{28,29}$. In rat motor neurons, for instance, the average rate of transport is approximately $3 \mathrm{~mm}$ per day, moving largely in SCb. However, actin rates in CNS neurons are much lower, and in most experiments, smaller 'peaks' of transport fractions were also seen (a smaller trailing peak of approximately $1.5 \mathrm{~mm}$ per day was seen in rat motor neurons, for example ${ }^{117}$ ). There is also a lagging trail of actin along axons as the radiolabelled 'wave' progresses, which may reflect actin deposition along axons ${ }^{99,116}$. Because actin is highly dynamic, any model of actin transport must also account for the dynamic exchange of monomeric and filamentous forms as well as explain the transport of actin in mature myelinated axons. Although the overall transport of actin in axons is well characterized, the underlying molecular mechanisms are essentially unknown. One study reported very-short-range saltatory motion of actin densities in cultured axons ${ }^{161}$, but it is unclear how this bidirectional short-range movement can lead to an overall slow, anterogradely biased transport. The actin hot spots and trails described above $\mathrm{e}^{148}$ might play a role in the axonal transport of actin; however, mechanistic details are lacking. Finally, although actin waves seen in developing neurites have been proposed to play a role in actin transport, this appears unlikely because their infrequent nature, periodicity and transient nature seem inconsistent with the slow, constitutive transport observed in radiolabelling experiments.
Function of axonal actin assemblies. Studies in non-neuronal cells have shown that, although longrange cargo transport is dependent on microtubules, actin filaments may contribute to short-range transport ${ }^{162}$. Actin in axon shafts has also been thought to play a similar role in assisting vesicle transport ${ }^{163}$. The traditional view that axons contained only short actin filaments, together with the intermingling of actin filaments and microtubule bundles in axons, seemed compatible with this model ${ }^{124,125}$. However, the recent discoveries of new actin assemblies in axons suggest that this simplistic view is at best incomplete.

From a mechanical perspective, submembrane rigid actin rings connected to a supple elastic cylinder of spectrins could provide both high resistance and flexibility to axons that may be critical in maintaining the axon form and function ${ }^{164,165}$. In support of this idea, axons of C. elegans lacking $\beta$-spectrin readily break when these worms move ${ }^{166}$, and the actin-spectrin undercoat is thought to maintain the mechanical properties of axons ${ }^{167,168}$. A combination of genetic mutants, pharmacologic treatments and SIM (see BOX 2) in D. melanogaster neurons allowed rapid screening of a large number of microtubule and actin regulators. This implicated the actin-spectrin undercoat in the maintenance of axonal microtubule organization $^{135}$. This could be mediated by the classical partner of spectrin, ankyrin, because large ankyrin isoforms also contribute to microtubule spacing and organization in D. melanogaster axons ${ }^{169}$. However, the function or functions of actin rings have still not been established. Perhaps more focused ways of perturbing actin, such as the confinement of axons within microfluidic devices ${ }^{170}$, the use of genetically encoded (and potentially subcellularly targeted) actin disassembly factors ${ }^{171}$ or optogenetic perturbation, may help.

Because actin filaments are a necessary component of the AIS diffusion barrier that restricts membrane diffusion between the cell body and the axon ${ }^{16,23}$, actin rings at the AIS might play a role in this diffusion barrier. Using correlative single-particle tracking and superresolution microscopy, it was recently found that in the AIS (but not the distal axon), the lateral mobility of a glycophosphatidylinositol (GPI)-anchored protein was restricted to the plasma membrane between actin rings ${ }^{172}$. Specifically, the movement of the GPI probe was shown to be slowed when it was close to actin rings but not when it was midway between them, where membrane proteins (channels and CAMs) are anchored to ankyrin-G. The authors of this study thus favoured an 'actin fence' model - in which the actin rings act as barriers to lateral membrane diffusion - rather than a 'pickets' model in which tethered membrane proteins between the rings act as barrier $^{24,65,173}$. As an alternative to corralling by actin itself, diffusion could also be impeded by the potassium channel Kv1.2 (also known as KCNA2), which (in contrast to other AIS membrane proteins) has been recently shown to localize precisely at actin rings ${ }^{132}$. It is also possible that other unidentified, AIS-specific 'pickets' might selectively impede the lateral diffusion of plasma membrane proteins at this locale, explaining the lack of restriction of diffusion seen in distal axons. 
En-passant boutons

Presynaptic specializations along axons that make contact with downstream neurons, as opposed to synaptic terminals at the extremity of axons. In hippocampal and cortical neuronal cultures, most presynapses are en-passant boutons.
The functions of deep actin assemblies such as hot spots and trails are not well understood ${ }^{174}$. Available data suggest that these dynamics help deposit actin at en-passant boutons and sustain presynaptic function ${ }^{148}$. As noted above, it also seems likely that the hot spots and trails have a role in the slow axonal transport of actin (and perhaps actin-binding proteins as well); however, it is unclear how this could happen mechanistically. The elongating actin trails resemble 'actin comets' observed in Listeria monocytogenes $^{175}$, and one possibility is that they may generate a propulsive force that could move vesicles or other cargoes. However, inhibition of actin trails does not have much effect on overall vesicle transport ${ }^{148}$ (although it remains possible that a subset of vesicles are transported in this manner). If all the hot spots and trails in an axon are considered to be part of an integrated actin 'network', the dynamic cytoskeletal organization could be seen as a source of assembly-competent actin monomers throughout the axon shaft. This may be an important homeostatic mechanism, allowing local actin-dependent physiological events (such as filopodial extension, axon branching, bouton formation and actin-dependent signalling) to occur rapidly, and future studies may provide clarity.

\section{Conclusion}

Easy to see but difficult to understand, the cytoskeleton of the axon shaft has long been the subject of speculative cartoons. Although much remains to be clarified, recent advances in super-resolution microscopy - along with the development of specific tools to probe or disrupt the cytoskeleton - now allow us to examine these assemblies with a spatial and temporal precision that was not possible before. The discovery of unique architectural assemblies of actin in axons forces us to question the roles traditionally assigned to actin, and one wonders if this might be true for the other cytoskeletal proteins as well. For instance, neurofilaments and mitochondria reportedly interact in axons ${ }^{176}$, but the underlying structural and functional associations are unclear. Moving forward, we can predict four general lines of investigation that are likely to have an impact on our understanding of the axonal cytoskeleton: further definition of the nanoscale architecture and dynamics of the cytoskeletal proteins and the generation of quantitative models; clarification of the individual roles of diverse cytoskeletal assemblies; appreciation of the architectural and mechanistic links between the cytoskeletal elements and axonal organelles, cytosolic proteins and the plasma membrane; and, ultimately, understanding the guiding principles that unite the entire axonal cytoskeletal meshwork to orchestrate physiological processes.

The axonal cytoskeleton is clearly a complex and sophisticated machinery with a menagerie of players. Even with the seemingly detailed knowledge that we have today - and the sophisticated tools that are at our disposal - one feels that the axonal cytoskeleton holds many more secrets, which must await the next generation of cytoskeleton gawkers.
1. Wilt, B. A. et al. Advances in light microscopy for neuroscience. Annu. Rev. Neurosci. 32, 435-506 (2009).

2. Maglione, M. \& Sigrist, S. J. Seeing the forest tree by tree: super-resolution light microscopy meets the neurosciences. Nat. Neurosci. 16, 790-797 (2013)

3. Pannese, E. Neurocytology. (Springer, 2015).

4. Wuerker, R. B. \& Kirkpatrick, J. B. Neuronal microtubules, neurofilaments, and microfilaments. Int. Rev. Cytol. 33, 45-75 (1972).

5. Frixione, E. The cytoskeleton of nerve cells in historic perspective. IBRO History of Neuroscience http:// ibro.info/wp-content/uploads/2012/12/TheCytoskeleton-of-Nerve-Cells-in-Historic-Perspective. pdf (2006).

6. Hirokawa, N. Cross-linker system between neurofilaments, microtubules, and membranous organelles in frog axons revealed by the quick-freeze deep-etching method. J. Cell Biol. 94, 129-142 (1982).

7. Schnapp, B. J. \& Reese, T. S. Cytoplasmic structure in rapid-frozen axons. J. Cell Biol. 94, 667-669 (1982) Using quick-freeze, deep-etching EM, references 6 and 7 provide the pictures that shaped our thinking about the axonal cytoskeleton for the following decades.

8. Shelanski, M. L. \& Taylor, E. W. Isolation of a protein subunit from microtubules. J. Cell Biol. 34, 549-554 (1967).

9. Borisy, G. G. \& Taylor, E. W. The mechanism of action of colchicine. Binding of colchincine-3H to cellular protein. J. Cell Biol. 34, 525-533 (1967).

10. Ishikawa, H., Bischoff, R. \& Holtzer, H. Formation of arrowhead complexes with heavy meromyosin in a variety of cell types. J. Cell Biol. 43, 312-328 (1969).

11. Leterrier, $\mathbf{C}$. The axon initial segment, 50 years later: $a$ nexus for neuronal organization and function. Curr. Top. Membr. 77, 185-233 (2016)

12. Kohno, K. Neurotubules contained within the dendrite and axon of Purkinje cell of frog. Bull. Tokyo Dent. Univ. 11, 411-442 (1964)

13. Palay, S., Sotelo, C., Peters, A. \& Orkand, P.

The axon hillock and the initial segment. J. Cell Biol. 38, 193-201 (1968).
14. Peters, A., Proskauer, C. C. \& Kaiserman-Abramof, I. R. The small pyramidal neuron of the rat cerebral cortex. The axon hillock and initial segment. J. Cell Biol. 39 604-619 (1968).

15. Hirokawa, N. \& Takemura, R. Molecular motors and mechanisms of directional transport in neurons. Nat. Rev. Neurosci. 6, 201-214 (2005).

16. Song, A.-H. et al. A selective filter for cytoplasmic transport at the axon initial segment. Cell 136, 1148-1160 (2009)

This study identifies an actin-based sorting of vesicular trafficking at the axon entrance whose mechanism is still debated today.

17. Chan-Palay, V. The tripartite structure of the undercoat in initial segments of Purkinje cell axons. Z. Anat. Entwicklungsgesch 139, 1-10 (1972)

18. Rasband, M. N. The axon initial segment and the maintenance of neuronal polarity. Nat. Rev. Neurosci. 11, 552-562 (2010)

19. Kordeli, E., Lambert, S. \& Bennett, V. AnkyrinG. A new ankyrin gene with neural-specific isoforms localized at the axonal initial segment and node of Ranvier. J. Biol. Chem. 270, 2352-2359 (1995).

20. Zhou, D. et al. AnkyrinG is required for clustering of voltage-gated $\mathrm{Na}$ channels at axon initial segments and for normal action potential firing. $J$. Cell Biol. 143, 1295-1304 (1998)

21. Berghs, S. et al. $\beta$ IV spectrin, a new spectrin localized at axon initial segments and nodes of ranvier in the central and peripheral nervous system. J. Cell Biol. 151, 985-1002 (2000)

22. Komada, M. \& Soriano, P. $\beta$ IV-spectrin regulates sodium channel clustering through ankyrin- $G$ at axon initial segments and nodes of Ranvier. J. Cell Biol. 156, 337-348 (2002)

23. Winckler, B., Forscher, P. \& Mellman, I. A diffusion barrier maintains distribution of membrane proteins in polarized neurons. Nature $397,698-70$ (1999)

24. Nakada, C. et al. Accumulation of anchored proteins forms membrane diffusion barriers during neuronal polarization. Nat. Cell Biol. 5, 626-632 (2003).
This article uses state-of-the-art single-particle tracking to demonstrate lipid immobilization at the AIS (in addition to protein immobilization shown in reference 23 ) and to probe the molecular basis of this diffusion barrier.

25. Hoffman, P. N. \& Lasek, R. J. The slow component of axonal transport. Identification of major structural polypeptides of the axon and their generality among mammalian neurons. J. Cell Biol. 66, 351-366 (1975).

26. Black, M. M. \& Lasek, R. J. Slow components of axonal transport: two cytoskeletal networks. J. Cell Biol. 86, 616-623 (1980)

27. Willard, M., Wiseman, M., Levine, J. \& Skene, P. Axonal transport of actin in rabbit retinal ganglion cells. J. Cell Biol. 81, 581-591 (1979).

28. Galbraith, J. A. \& Gallant, P. E. Axonal transport of tubulin and actin. J. Neurocytol. 29, 889-911 (2000).

29. Roy, S. Seeing the unseen: the hidden world of slow axonal transport. Neuroscientist 20, 71-81 (2014).

30. Wang, Y., Shyy, J. Y.-J. \& Chien, S. Fluorescence proteins, live-cell imaging, and mechanobiology: seeing is believing. Annu. Rev. Biomed. Eng. 10, 1-38 (2008).

31. Kuczmarski, E. R. \& Rosenbaum, J. L. Studies on the organization and localization of actin and myosin in neurons. J. Cell Biol. 80, 356-371 (1979).

32. Alonso, G., Gabrion, J., Travers, E. \& Assenmacher, I. Ultrastructural organization of actin filaments in neurosecretory axons of the rat. Cell Tissue Res. 214 323-341 (1981)

33. Nagele, R. G., Kosciuk, M. C., Hunter, E. T., Bush, K. T. \& Lee, H. Immunoelectron microscopic localization of actin in neurites of cultured embryonic chick dorsal root ganglia: actin is a component of granular, microtubule-associated crossbridges. Brain Res. 474 279-286 (1988)

34. Letourneau, P. C. Differences in the organization of actin in the growth cones compared with the neurites of cultured neurons from chick embryos. J. Cell Biol. 97, 963-973 (1983)

35. Letourneau, P. C. Actin in axons: stable scaffolds and dynamic filaments. Results Probl. Cell Differ. 48 , 65-90 (2009). 
36. Wang, L., Ho, C. L., Sun, D., Liem, R. K. \& Brown, A. Rapid movement of axonal neurofilaments interrupted by prolonged pauses. Nat. Cell Biol. 2, 137-141 (2000).

37. Roy, S. et al. Neurofilaments are transported rapidly but intermittently in axons: implications for slow axonal transport. J. Neurosci. 20, 6849-6861 (2000).

References 36 and 37 show rapid, intermittent movements of neurofilaments along axons, establishing the 'stop and go' model of neurofilament transport.

38. Stepanova, T. et al. Visualization of microtubule growth in cultured neurons via the use of EB3-GFP (end-binding protein 3-green fluorescent protein). J. Neurosci. 23, 2655-2664 (2003).

This report describes pioneering the use of fluorescent EBs to detect the orientation of dynamic axonal microtubules, which is refined and extended in reference 39

39. Yau, K. W. et al. Dendrites in vitro and in vivo contain microtubules of opposite polarity and axon formation correlates with uniform plus-end-out microtubule orientation. J. Neurosci. 36

1071-1085 (2016)

40. Conde, C. \& Caceres, A. Microtubule assembly, organization and dynamics in axons and dendrites. Nat. Rev. Neurosci. 10, 319-332 (2009).

41. Heidemann, S. R., Landers, J. M. \& Hamborg, M. A Polarity orientation of axonal microtubules. J. Cell Biol. 91, 661-665 (1981)

42. Baas, P. W., Deitch, J. S., Black, M. M. \& Banker, G. A. Polarity orientation of microtubules in hippocampal neurons: uniformity in the axon and nonuniformity in the dendrite. Proc. Natl Acad. Sci. USA 85, 8335-8339 (1988).

43. Baas, P. W. \& Lin, S. Hooks and comets: the story of microtubule polarity orientation in the neuron. Dev. Neurobiol. 71, 403-418 (2011).

44. van de Willige, D. Hoogenraad, C. C. \& Akhmanova, A. Microtubule plus-end tracking proteins in neuronal development. Cell. Mol. Life Sci. 73, 2053-2077 (2016)

45. Kleele, T. et al. An assay to image neuronal microtubule dynamics in mice. Nat. Commun. 5, 4827 (2014).

46. Waxman, S. G. \& Kocsis, J. D. The Axon. (Oxford Univ. Press, 1995)

47. Peters, A. \& Vaughn, J. E. Microtubules and filaments in the axons and astrocytes of early postnatal rat optic nerves. J. Cell Biol. 32, 113-119 (1967).

48. Yu, W. \& Baas, P. W. Changes in microtubule number and length during axon differentiation. J. Neurosci. 14, 2818-2829 (1994).

49. Bray, D. \& Bunge, M. B. Serial analysis of microtubules in cultured rat sensory axons. J. Neurocytol. 10, 589-605 (1981).

50. Burton, P. R. Microtubules of frog olfactory axons: their length and number/axon. Brain Res. 409 71-78 (1987).

51. Burton, P. R. Ultrastructural studies of microtubules and microtubule organizing centers of the vertebrate olfactory neuron. Microsc. Res. Tech. 23, 142-156 (1992).

52. Tsukita, S. \& Ishikawa, H. The cytoskeleton in myelinated axons: serial section study. Biomed. Res. 2, 424-437 (1981)

53. Yogev, S., Cooper, R., Fetter, R., Horowitz, M. \& Shen, K. Microtubule organization determines axonal transport dynamics. Neuron 92, 449-460 (2016). This article uses methods based on fluorescence and live-cell imaging to comprehensively map the organization of axonal microtubules in $C$. elegans neurons and correlate it to vesicular transport events.

54. Chalfie, M. \& Thomson, J. N. Organization of neuronal microtubules in the nematode Caenorhabditis elegans. J. Cell Biol. 82, 278-289 (1979).

55. Mudrakola, H. V., Zhang, K. \& Cui, B. Optically resolving individual microtubules in live axons. Structure 17, 1433-1441 (2009).

56. Mikhaylova, M. et al. Resolving bundled microtubules using anti-tubulin nanobodies. Nat. Commun. 6, 7933 (2015).

This study demonstrates the need for small probes (nanobodies) in addition to super-resolution microscopy to probe the organization of microtubules within neuronal bundles

57. van Coevorden-Hameete, M. H. et al. Antibodies to TRIM46 are associated with paraneoplastic neurological syndromes. Ann. Clin. Trans/ Neurol. 4 680-686 (2017)
58. van Beuningen, S. F. B. et al. TRIM46 controls neuronal polarity and axon specification by driving the formation of parallel microtubule arrays. Neuron $\mathbf{8 8}$, 1208-1226 (2015)

59. Leterrier, C. $\&$ Dargent, B. No Pasaran! Role of the axon initial segment in the regulation of protein transport and the maintenance of axonal identity. Semin. Cell Dev. Biol. 27, 44-51 (2014).

60. Satake, T. et al. MTCL1 plays an essential role in maintaining Purkinje neuron axon initial segment. EMBO J. 36, 1227-1242 (2017).

61. Nakata, T. \& Hirokawa, N. Microtubules provide directional cues for polarized axonal transport through interaction with kinesin motor head. J. Cell Biol. 162, 1045-1055 (2003).

62. Nakata, T., Niwa, S., Okada, Y., Perez, F. \& Hirokawa, N. Preferential binding of a kinesin-1 motor to GTP-tubulin-rich microtubules underlies polarized vesicle transport. J. Cell Biol. 194 245-255 (2011).

63. Leterrier, C. et al. End-binding proteins EB3 and EB 1 link microtubules to ankyrin $\mathrm{G}$ in the axon initial segment. Proc. Natl Acad. Sci. USA 108, 8826-8831 (2011)

64. Freal, A. et al. Cooperative interactions between $480 \mathrm{kDa}$ ankyrin-G and EB proteins assemble the axon initial segment. J. Neurosci. 36, 4421-4433 (2016).

65. Leterrier, C. et al. Nanoscale architecture of the axon initial segment reveals an organized and robust scaffold. Cell Rep. 13, 2781-2793 (2015).

This article uses STORM to determine the architecture of the axon initial segment scaffold, highlighting the capability of super-resolution microscopy to delineate molecular complexes in neurons.

66. Yu, W., Centonze, V. E., Ahmad, F. J. \& Baas, P. W. Microtubule nucleation and release from the neuronal centrosome. J. Cell Biol. 122, 349-359 (1993).

67. Ahmad, F. J., Joshi, H. C., Centonze, V. E. \& Baas, P. W. Inhibition of microtubule nucleation at the neuronal centrosome compromises axon growth. Neuron 12, 271-280 (1994).

68. Baas, P. W. Microtubules and neuronal polarity: lessons from mitosis. Neuron 22, 23-31 (1999).

69. Stiess, M. et al. Axon extension occurs independently of centrosomal microtubule nucleation. Science $\mathbf{3 2 7}$ 704-707 (2010).

70. Nguyen, M. M., Stone, M. C. \& Rolls, M. M. Microtubules are organized independently of the centrosome in Drosophila neurons. Neural Dev. 6, 38 (2011)

71. Yonezawa, S., Shigematsu, M., Hirata, K. \& Hayashi, K. Loss of $\gamma$-tubulin, GCP-WD/NEDD1 and CDK5RAP2 from the centrosome of neurons in developing mouse cerebral and cerebellar cortex. Acta Histochem. Cytochem. 48, 145-152 (2015).

72. Yau, K. W. et al. Microtubule minus-end binding protein CAMSAP2 controls axon specification and dendrite development. Neuron 82, 1058-1073 (2014)

73. Kuijpers, M. \& Hoogenraad, C. C. Centrosomes, microtubules and neuronal development. Mol. Cell. Neurosci. 48, 349-358 (2011).

74. Ori-McKenney, K. M., Jan, L. Y. ¿ Jan, Y.-N. Golgi outposts shape dendrite morphology by functioning as sites of acentrosomal microtubule nucleation in neurons. Neuron 76, 921-930 (2012)

75. Delandre, C., Amikura, R. \& Moore, A. W. Microtubule nucleation and organization in dendrites. Cell Cycle 15, 1685-1692 (2016)

76. Sănchez-Huertas, C. et al. Non-centrosomal nucleation mediated by augmin organizes microtubules in postmitotic neurons and controls axonal microtubule polarity. Nat. Commun. 7, 12187 (2016)

77. Kapitein, L. C. \& Hoogenraad, C. C. Building the neuronal microtubule cytoskeleton. Neuron 87 492-506 (2015).

78. Howard, J. \& Hyman, A. A. Growth, fluctuation and switching at microtubule plus ends. Nat. Rev. Mol. Cell Biol. 10, 569-574 (2009).

79. Akhmanova, A. \& Hoogenraad, C. C. Microtubule minus-end-targeting proteins. Curr. Biol. 25 , R162-R171 (2015)

80. Wu, J. \& Akhmanova, A. Microtubule-organizing centers. Annu. Rev. Cell Dev. Biol. http://dx.doi. org/10.1146/annurev-cellbio-100616-060615 (2017)

81. Goodwin, S. S. \& Vale, R. D. Patronin regulates the microtubule network by protecting microtubule minus ends. Cell 143, 263-274 (2010).
82. Richardson, C. E. et al. PTRN-1, a microtubule minus end-binding CAMSAP homolog, promotes microtubule function in Caenorhabditis elegans neurons. eLife 3 , e01498 (2014)

83. Marcette, J. D., Chen, J. J. \& Nonet, M. L. The Caenorhabditis elegans microtubule minus-end binding homolog PTRN-1 stabilizes synapses and neurites. elife 3, e01637 (2014).

84. Baas, P. W., Rao, A. N., Matamoros, A. J. \& Leo, L. Stability properties of neuronal microtubules. Cytoskeleton 73, 442-460 (2016).

85. Baas, P. W., Slaughter, T., Brown, A. \& Black, M. M Microtubule dynamics in axons and dendrites. J. Neurosci. Res. 30, 134-153 (1991).

86. Baas, P. W. \& Black, M. M. Individual microtubules in the axon consist of domains that differ in both composition and stability. J. Cell Biol. 111, 495-509 (1990).

87. Ahmad, F. J., Pienkowski, T. P. \& Baas, P. W. Regional differences in microtubule dynamics in the axon. J. Neurosci. 13, 856-866 (1993).

88. Janke, C. \& Bulinski, J. C. Post-translational regulation of the microtubule cytoskeleton: mechanisms and functions. Nat. Rev. Mol. Cell Biol. 12, 773-786 (2011).

89. Song, Y. et al. Transglutaminase and polyamination of tubulin: posttranslational modification for stabilizing axonal microtubules. Neuron 78 109-123 (2013)

90. Sirajuddin, M., Rice, L. M. \& Vale, R. D. Regulation of microtubule motors by tubulin isotypes and posttranslational modifications. Nat. Cell Biol. 16, 335-344 (2014)

91. Janke, C. \& Kneussel, M. Tubulin post-translational modifications: encoding functions on the neuronal microtubule cytoskeleton. Trends Neurosci. 33 362-372 (2010)

92. Xu, Z. et al. Microtubules acquire resistance from mechanical breakage through intralumenal acetylation. Science 356, 328-332 (2017).

93. Hammond, J. W. et al. Posttranslational modifications of tubulin and the polarized transport of kinesin- 1 in neurons. Mol. Biol. Cell 21, 572-583 (2010).

94. Konishi, Y. \& Setou, M. Tubulin tyrosination navigates the kinesin-1 motor domain to axons. Nat. Neurosci. 12, 559-567 (2009).

95. Tapia, M., Wandosell, F. \& Garrido, J. J. Impaired function of HDAC6 slows down axonal growth and interferes with axon initial segment development. PLOS ONE 5, e12908 (2010).

96. Dimitrov, A. et al. Detection of GTP-tubulin conformation in vivo reveals a role for GTP remnants in microtubule rescues. Science 322, 1353-1356 (2008).

97. Cassimeris, L., Guglielmi, L., Denis, V., Larroque, C. \& Martineau, P. Specific in vivo labeling of tyrosinated $\alpha$-tubulin and measurement of microtubule dynamics using a GFP tagged, cytoplasmically expressed recombinant antibody. PLOS ONE 8, e59812 (2013).

98. Borowiak, M. et al. Photoswitchable inhibitors of microtubule dynamics optically control mitosis and cell death. Cell 162, 403-411 (2015)

99. Tashiro, T. \& Komiya, Y. Organization and slow axonal transport of cytoskeletal proteins under normal and regenerating conditions. Mol. Neurobiol. 6, 301-311 (1992).

100. Hoffman, P. N., Lopata, M. A., Watson, D. F. \& Luduena, R. F. Axonal transport of class II and III $\beta$-tubulin: evidence that the slow component wave represents the movement of only a small fraction of the tubulin in mature motor axons. J. Cell Biol. 119 595-604 (1992)

101. Terasaki, M., Schmidek, A., Galbraith, J. A., Gallant, P. E. \& Reese, T. S. Transport of cytoskeletal elements in the squid giant axon. Proc. Natl Acad. Sci. USA 92, 11500-11503 (1995).

102. Dent, E. W., Callaway, J. L., Szebenyi, G., Baas, P. W. \& Kalil, K. Reorganization and movement of microtubules in axonal growth cones and developing interstitial branches. J. Neurosci. 19, 8894-8908 (1999).

103. Galbraith, J. A., Reese, T. S., Schlief, M. L. \& Gallant, P. E. Slow transport of unpolymerized tubulin and polymerized neurofilament in the squid giant axon. Proc. Natl Acad. Sci. USA 96, 11589-11594 (1999).

104. Terada, S., Kinjo, M. \& Hirokawa, N. Oligomeric tubulin in large transporting complex is transported via kinesin in squid giant axons. Cell 103, 141-155 (2000).

105. Wang, L. \& Brown, A. Rapid movement of microtubules in axons. Curr. Biol. 12, 1496-1501 (2002). 
106. Brown, A. Axonal transport of membranous and nonmembranous cargoes: a unified perspective. J. Cell Biol. 160, 817-821 (2003)

107. He, Y. et al. Role of cytoplasmic dynein in the axonal transport of microtubules and neurofilaments. J. Cell Biol. 168, 697-703 (2005)

108. Rao, A. N. et al. Cytoplasmic dynein transports axonal microtubules in a polarity-sorting manner. Cell Rep. 19, 2210-2219 (2017)

109. Ganguly, A. et al. Hsc70 chaperone activity is required for the cytosolic slow axonal transport of synapsin. J. Cell Biol. 216, 2059-2074 (2017).

110. Jolly, A. L. et al. Kinesin-1 heavy chain mediates microtubule sliding to drive changes in cell shape. Proc. Natl Acad. Sci. USA 107, 12151-12156 (2010).

111. Keating, T. J., Peloquin, J. G., Rodionov, V. I., Momcilovic, D. \& Borisy, G. G. Microtubule release from the centrosome. Proc. Natl Acad. Sci. USA 94 5078-5083 (1997).

112. Hirokawa, N., Glicksman, M. A. \& Willard, M. B. Organization of mammalian neurofilament polypeptides within the neuronal cytoskeleton. J. Cell Biol. 98, 1523-1536 (1984).

113. Laser-Azogui, A., Kornreich, M., Malka-Gibor, E. \& Beck, R. Neurofilament assembly and function during neuronal development. Curr. Opin. Cell Biol. 32 , 92-101 (2015).

114. Uchida, A., Colakoglu, G., Wang, L., Monsma, P. C. \& Brown, A. Severing and end-to-end annealing of neurofilaments in neurons. Proc. Natl Acad. Sci. USA 110, E2696-E2705 (2013).

115. Leduc, C. \& Etienne-Manneville, S. Regulation of microtubule-associated motors drives intermediate filament network polarization. J. Cell Biol. 216, 1689-1703 (2017).

116. Black, M. M. \& Lasek, R. J. Axonal transport of actin: slow component $b$ is the principal source of actin for the axon. Brain Res. 171, 401-413 (1979).

117. McQuarrie, I. G., Brady, S. T. \& Lasek, R. J. Diversity in the axonal transport of structural proteins: major differences between optic and spinal axons in the rat. J. Neurosci. 6, 1593-1605 (1986)

118. Nixon, R. A. \& Logvinenko, K. B. Multiple fates of newly synthesized neurofilament proteins: evidence for a stationary neurofilament network distributed nonuniformly along axons of retinal ganglion cell neurons. J. Cell Biol. 102, 647-659 (1986).

119. Hirokawa, N., Funakoshi, S. T. \& Takeda, S. Slow axonal transport: the subunit transport model. Trends Cell Biol. 7, 384-388 (1997).

120. Baas, P. W. \& Brown, A. Slow axonal transport: the polymer transport model. Trends Cell Biol. 7 380-384 (1997)

References 119 and 120 offer a summary of the 1990 s debate on the mechanism of slow axonal transport for cytoskeletal components.

121. Yan, Y. \& Brown, A. Neurofilament polymer transport in axons. J. Neurosci. 25, 7014-7021 (2005).

122. Uchida, A., Alami, N. H. \& Brown, A. Tight functional coupling of kinesin- $1 \mathrm{~A}$ and dynein motors in the bidirectional transport of neurofilaments. Mol. Biol. Cell 20, 4997-5006 (2009)

123. LeBeux, Y. J. \& Willemot, J. An ultrastructural study of the microfilaments in rat brain by means of heavy meromyosin labeling. I. The perikaryon, the dendrites and the axon. Cell Tissue Res. 160, 1-36 (1975).

124. Fath, K. R. \& Lasek, R. J. Two classes of actin microfilaments are associated with the inner cytoskeleton of axons. J. Cell Biol. 107, 613-621 (1988).

125. Bearer, E. L. \& Reese, T. S. Association of actin filaments with axonal microtubule tracts. J. Neurocytol. 28, 85-98 (1999).

126. Spooner, B. S. \& Holladay, C. R. Distribution of tubulin and actin in neurites and growth cones of differentiating nerve cells. Cytoskeleton 1, 167-178 (1981)

127. Xu, K., Zhong, G. \& Zhuang, X. Actin, spectrin, and associated proteins form a periodic cytoskeletal structure in axons. Science 339, 452-456 (2013). This study identifies the periodic organization of submembrane axonal actin, with actin rings regularly spaced every $190 \mathrm{~nm}$ by spectrins.

128. Bennett, V., Davis, J. Q. \& Fowler, W. E. Brain spectrin a membrane-associated protein related in structure and function to erythrocyte spectrin. Nature 299, 126-131 (1982)

129. Glenney, J. R., Glenney, P. \& Weber, K. F-Actinbinding and cross-linking properties of porcine brain fodrin, a spectrin-related molecule. J. Biol. Chem. 257, 9781-9787 (1982).
130. Lukinavicius, G. et al. Fluorogenic probes for livecell imaging of the cytoskeleton. Nat. Methods 11 $731-733$ (2014)

131. D'Este, E., Kamin, D., Göttfert, F., El-Hady, A. \& Hell, S. W. STED nanoscopy reveals the ubiquity of subcortical cytoskeleton periodicity in living neurons. Cell Rep. 10, 1246-1251 (2015).

132. D’Este, E., Kamin, D., Balzarotti, F. \& Hell, S. W. Ultrastructural anatomy of nodes of Ranvier in the peripheral nervous system as revealed by STED microscopy. Proc. Natl Acad. Sci. USA 114 E191-E199 (2016)

133. D'Este, E. et al. Subcortical cytoskeleton periodicity throughout the nervous system. Sci. Rep. 6, 22741 (2016).

134. He, J. et al. Prevalent presence of periodic actinspectrin-based membrane skeleton in a broad range of neuronal cell types and animal species. Proc. Natl Acad. Sci. USA 113, 6029-6034 (2016).

135. Qu, Y., Hahn, I., Webb, S. E. D. \& Prokop, A. Periodic actin structures in neuronal axons are required to maintain microtubules. Mol. Biol. Cell 28, 296-308 (2016)

136. Sidenstein, S. C. et al. Multicolour multilevel STED nanoscopy of actin/spectrin organization at synapses. Sci. Rep. 6, 26725 (2016)

137. Bär, J., Kobler, O., van Bommel, B. \& Mikhaylova, M. Periodic F-actin structures shape the neck of dendritic spines. Sci. Rep. 6, 37136 (2016).

138. Han, B., Zhou, R., Xia, C. \& Zhuang, X. Structural organization of the actin-spectrin-based membrane skeleton in dendrites and soma of neurons. Proc. Natl Acad. Sci. USA 114 E6678-E6685 (2017)

139. Zhong, G. et al. Developmental mechanism of the periodic membrane skeleton in axons. eLife 3, 194 (2014)

140. Leite, S. C. et al. The actin-binding protein $\alpha$-adducin is required for maintaining axon diameter. Cell Rep. 15, 490-498 (2016).

References 135, 139 and 140 present the first information about the mechanisms of actin ring assembly and maintenance.

141. Leite, S. C. $\&$ Sousa, M. M. The neuronal and actin commitment: why do neurons need rings? Cytoskeleton 73, 424-434 (2016).

142. Galiano, M. R. et al. A distal axonal cytoskeleton forms an intra-axonal boundary that controls axon initial segment assembly. Cell 149, 1125-1139 (2012)

143. Watanabe, K. et al. Networks of polarized actin filaments in the axon initial segment provide a mechanism for sorting axonal and dendritic proteins. Cell Rep. 2, 1546-1553 (2012).

This study identifies actin patches inside the AIS and, together with reference 245 , proposed that they regulate vesicular entrance into the axon.

144. Jones, S. L., Korobova, F. \& Svitkina, T. Axon initia segment cytoskeleton comprises a multiprotein submembranous coat containing sparse actin filaments. J. Cell Biol. 205, 67-81 (2014).

145. Al-Bassam, S., Xu, M., Wandless, T. J. \& Arnold, D. B. Differential trafficking of transport vesicles contributes to the localization of dendritic proteins. Cell Rep. 2, 89-100 (2012).

146. Janssen, A. F. J. et al. Myosin-V induces cargo immobilization and clustering at the axon initial segment. Front. Cell Neurosci. 11, 89 (2017).

147. Nirschl, J. J., Ghiretti, A. E. \& Holzbaur, E. L. F. The impact of cytoskeletal organization on the local regulation of neuronal transport. Nat. Rev. Neurosci. 18, 585-597 (2017).

This recent review gives a contemporary view of local regulation of the transport machinery in axons, dendrites and synapses.

148. Ganguly, A. et al. A dynamic formin-dependent deep F-actin network in axons. J. Cell Biol. 104 20576-20417 (2015)

This study presents the discovery of new actin structures within axons: static, intermittent hot spots and dynamic filamentous trails spurting from them

149. Ruthel, G. \& Banker, G. A. Actin-dependent anterograde movement of growth-cone-like structures along growing hippocampal axons: a novel form of axonal transport? Cell. Motil. Cytoskeleton 40, 160-173 (1998)

150. Flynn, K. C. et al. ADF/Cofilin-mediated actin retrograde flow directs neurite formation in the developing brain. Neuron 76, 1091-1107 (2012).
151. Tint, I., Jean, D., Baas, P. W. \& Black, M. M. Doublecortin associates with microtubules preferentially in regions of the axon displaying actinrich protrusive structures. J. Neurosci. 29, 10995-11010 (2009)

152. Katsuno, H. \& Sakumura, Y. Actin migration driven by directional assembly and disassembly of membraneanchored actin filaments. Cell Rep. 12, 648-660 (2015).

This article combines live-cell imaging micromanipulation and force measurements to detail the organization and mechanisms of axonal actin waves.

153. Winans, A. M., Collins, S. R. \& Meyer, T. Waves of actin and microtubule polymerization drive microtubulebased transport and neurite growth before single axon formation. elife 5, e1 2387 (2016).

154. Tomba, C. et al. Geometrical determinants of neuronal actin waves. Front. Cell Neurosci. 11, 86 (2017).

155. Flynn, K. C., Pak, C. W., Shaw, A. E., Bradke, F. \& Bamburg, J. R. Growth cone-like waves transport actin and promote axonogenesis and neurite branching. Dev. Neurobiol. 69, 761-779 (2009).

156. Roy, S. Waves, rings, and trails: the scenic landscape of axonal actin. J. Cell Biol. 212, 131-134 (2016).

157. Allard, J. \& Mogilner, A. Traveling waves in actin dynamics and cell motility. Curr. Opin. Cell Biol. 25, 107-115 (2013).

158. Arnold, D. B. \& Gallo, G. Structure meets function: actin filaments and myosin motors in the axon. J. Neurochem. 129, 213-220 (2013).

159. Spillane, M. et al. The actin nucleating Arp $2 / 3$ complex contributes to the formation of axonal filopodia and branches through the regulation of actin patch precursors to filopodia. Dev. Neurobiol. 71 , 747-758 (2011)

160. Armijo-Weingart, L. $\&$ Gallo, G. It takes a village to raise a branch: Cellular mechanisms of the initiation of axon collateral branches. Mol. Cell. Neurosci. http:// dx.doi.org/10.1016/j.mcn.2017.03.007 (2017).

161. Chetta, J., Love, J. M., Bober, B. G. \& Shah, S. B. Bidirectional actin transport is influenced by microtubule and actin stability. Cell. Mol. Life Sci. 72 , 4205-4220 (2015).

162. Rogers, S. L. \& Gelfand, V. I. Myosin cooperates with microtubule motors during organelle transport in melanophores. Curr. Biol. 8, 161-164 (1998).

163. Bridgman, P. C. Myosin-dependent transport in neurons. J. Neurobiol. 58, 164-174 (2004).

164. Lai, L. \& Cao, J. Spectrins in axonal cytoskeletons: dynamics revealed by extensions and fluctuations. J. Chem. Phys. 141, 015101 (2014).

165. Zhang, Y. et al. Modeling of the axon membrane skeleton structure and implications for its mechanical properties. PLoS Comput. Biol. 13, e1005407 (2017).

166. Hammarlund, M., Jorgensen, E. M. \& Bastiani, M. J. Axons break in animals lacking beta-spectrin. J. Cell Biol. 176, 269-275 (2007)

167. Krieg, M. et al. Genetic defects in $\beta$-spectrin and tau sensitize $C$. elegans axons to movement-induced damage via torque-tension coupling. eLife 6, 1187 (2017).

168. Krieg, M., Dunn, A. R. \& Goodman, M. B. Mechanical control of the sense of touch by $\beta$-spectrin. Nat. Cell Biol. 16, 224-233 (2014).

References 167 and 168 combine in vivo force measurements, mutant analysis, super-resolution microscopy and modelling to explore the role of microtubules and the actin-spectrin submembrane scaffold in the mechanical robustness of axons.

169. Stephan, R. et al. Hierarchical microtubule organization controls axon caliber and transport and determines synaptic structure and stability. Dev. Cell 33, 5-21 (2015)

170. Taylor, A. M., Dieterich, D. C., Ito, H. T., Kim, S. A. \& Schuman, E. M. Microfluidic local perfusion chambers for the visualization and manipulation of synapses. Neuron 66, 57-68 (2010)

171. Harterink, M. et al. DeActs: genetically encoded tools for perturbing the actin cytoskeleton in single cells. Nat. Methods 14, 479-482 (2017).

172. Albrecht, D. et al. Nanoscopic compartmentalization of membrane protein motion at the axon initial segment. J. Cell Biol. 215, 37-46 (2016). This study combines single-particle tracking and super-resolution microscopy to detail how the AIS surface diffusion barrier forms and operates.

173. Brachet, A. et al. Ankyrin G restricts ion channel diffusion at the axonal initial segment before the establishment of the diffusion barrier. J. Cell Biol. 191, 383-395 (2010). 
174. Dance, A. Inner workings: uncovering the neuron's internal skeleton. Proc. Natl Acad. Sci. USA 113, 13931-13933 (2016)

175. Tilney, L. G. \& Portnoy, D. A. Actin filaments and the growth, movement, and spread of the intracellular bacterial parasite, Listeria monocytogenes. J. Cell Biol. 109, 1597-1608 (1989).

176. Wagner, O. I. et al. Mechanisms of mitochondrianeurofilament interactions. J. Neurosci. 23, 9046-9058 (2003).

177. Schermelleh, L., Heintzmann, R. \& Leonhardt, H. A guide to super-resolution fluorescence microscopy. J. Cell Biol. 190, 165-175 (2010).

178. Toomre, D. \& Bewersdorf, J. A new wave of cellular imaging. Annu. Rev. Cell Dev. Biol. 26, 285-314 (2010).

179. Fornasiero, E. F. \& Opazo, F. Super-resolution imaging for cell biologists. Bioessays 37, 436-451 (2015).

180. Rust, M. J., Bates, M. \& Zhuang, X. Sub-diffraction-limit imaging by stochastic optical reconstruction microscopy (STORM). Nat. Methods 3, 793-795 (2006).

181. Betzig, E. et al. Imaging intracellular fluorescent proteins at nanometer resolution. Science 313 , 1642-1645 (2006).

182. Gustafsson, M. G. Surpassing the lateral resolution limit by a factor of two using structured illumination microscopy. J. Microsc. 198, 82-87 (2000).

183. Gustafsson, M. G. L. Nonlinear structured-illumination microscopy: wide-field fluorescence imaging with theoretically unlimited resolution. Proc. Natl Acad. Sci. USA 102, 13081-13086 (2005).

184. Klar, T. A., Jakobs, S., Dyba, M., Egner, A. \& Hell, S. W. Fluorescence microscopy with diffraction resolution barrier broken by stimulated emission. Proc. Natl Acad. Sci. USA 97, 8206-8210 (2000).

185. Dotti, C. G., Sullivan, C. \& Banker, G. A. The establishment of polarity by hippocampal neurons in culture. J. Neurosci. 8, 1454-1468 (1988).

186. Dent, E. W. et al. Filopodia are required for cortical neurite initiation. Nat. Cell Biol. 9, 1347-1359 (2007).
187. Flynn, K. C. The cytoskeleton and neurite initiation. BioArchitecture 3, 86-109 (2014)

188. Jacobson, C., Schnapp, B. \& Banker, G. A. A. Change in the selective translocation of the kinesin-1 motor domain marks the initial specification of the axon. Neuron 49, 797-804 (2006).

189. Randlett, O., Poggi, L., Zolessi, F. R. \& Harris, W. A The oriented emergence of axons from retinal ganglion cells is directed by laminin contact in vivo. Neuron 70, 266-280 (2011).

190. Lewis, T. L., Courchet, J. \& Polleux, F. Cell biology in neuroscience: cellular and molecular mechanisms underlying axon formation, growth, and branching. J. Cell Biol. 202, 837-848 (2013).

191. Bentley, M. \& Banker, G. A. The cellular mechanisms that maintain neuronal polarity. Nat. Rev. Neurosci. 17, 611-622 (2016)

192. Schelski, M. \& Bradke, F. Neuronal polarization: from spatiotemporal signaling to cytoskeletal dynamics. Mol. Cell. Neurosci. http://dx.doi.org/10.1016/j. mcn.2017.03.008. (2017).

193. Bradke, F. \& Dotti, C. G. Neuronal polarity: vectorial cytoplasmic flow precedes axon formation. Neuron 19 , 1175-1186 (1997).

194. Bradke, F. \& Dotti, C. G. The role of local actin instability in axon formation. Science 283 1931-1934 (1999).

195. Witte, H., Neukirchen, D. \& Bradke, F. Microtubule stabilization specifies initial neuronal polarization. J. Cell Biol. 180, 619-632 (2008).

196. Omotade, O. F., Pollitt, S. L. \& Zheng, J. Q. Actin-based growth cone motility and guidance. Mol. Cell. Neurosci. http://dx.doi.org/10.1016/j.mcn.2017.03.001 (2017).

197. Vitriol, E. A. \& Zheng, J. Q. Growth cone travel in space and time: the cellular ensemble of cytoskeleton, adhesion, and membrane. Neuron 73, 1068-1081 (2012).

198. Dent, E. W., Gupton, S. L. \& Gertler, F. B. The growth cone cytoskeleton in axon outgrowth and guidance. Cold Spring Harb. Perspect. Biol. 3, a001800 (2011).
199. Nozumi, M., Nakatsu, F., Katoh, K. \& Igarashi, M. Coordinated movement of vesicles and actin bundles during nerve growth revealed by superresolution microscopy. Cell Rep. 18, 2203-2216 (2017).

200. Hedstrom, K. et al. Neurofascin assembles a specialized extracellular matrix at the axon initial segment. J. Cell Biol. 178, 875-886 (2007).

201. Boiko, T. et al. Ankyrin-dependent and -independent mechanisms orchestrate axonal compartmentalization of L1 family members neurofascin and L1/neuron-glia cell adhesion molecule. J. Neurosci. 27, 590-603 (2007).

202. Kalil, K. \& Dent, E. W. Branch management: mechanisms of axon branching in the developing vertebrate CNS. Nat. Rev. Neurosci. 15, 7-18 (2014).

203. McAllister, A. Dynamic aspects of CNS synapse formation. Annu. Rev. Neurosci. 30, 425-450 (2007).

\section{Acknowledgements}

Work in the Leterrier laboratory is supported by the Centre National de la Recherche Scientifique (CNRS) Action Thématique et Incitative sur Programme (ATIP)-Avenir programme $\mathrm{AO} 2016$. Work in the Roy laboratory is supported by US National Institutes of Health $(\mathrm{NIH})$ grants R01NS075233, R01AG048218 and R21 AG052404.

\section{Author contributions}

C.L., P.D and S.R. contributed to researching data for the article, making contributions to discussion of content and writing. C.L. and S.R. contributed equally to writing, reviewing and editing of the manuscript before submission.

Competing interests statement

The authors declare that there is no competing interest.

Publisher's note

Springer Nature remains neutral with regard to jurisdictional claims in published maps and institutional affiliations. 